\title{
Under the radar
}

Harmful industries' digital

marketing to Australian children

A report prepared by VicHealth and co-contributors

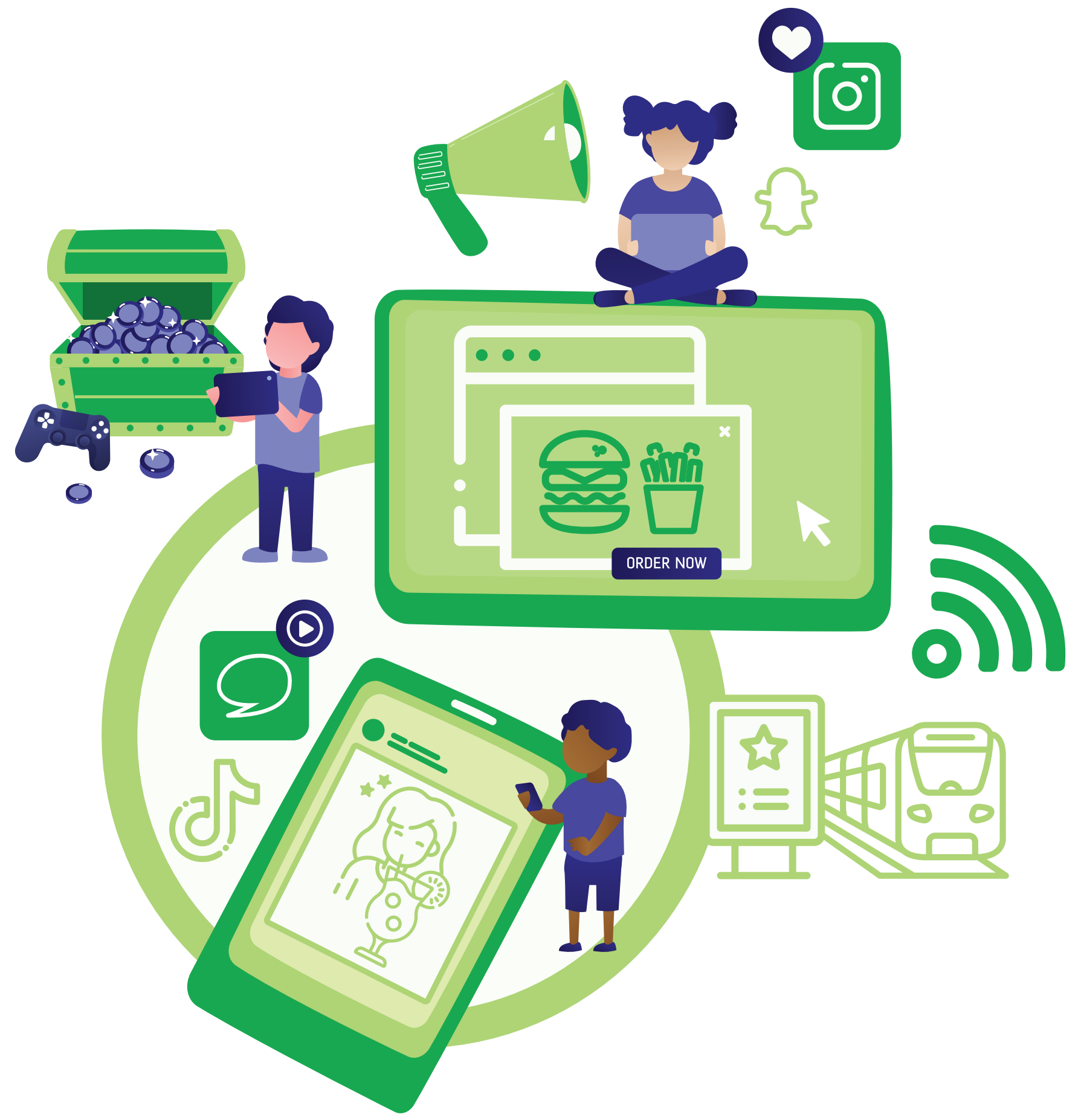

facien fave 


\title{
Foreword from VicHealth CEO
}

\author{
Australian children are engaging with technology more than ever before. In 2020, \\ during the coronavirus pandemic, the digital world has cemented itself as a \\ foundational element of children's lives. Children have had to rely on digital technology \\ for education, social connection and entertainment. \\ While children explore, learn and connect online, they are surrounded by digital marketing of harmful \\ products via websites, social media, gaming and influencers. On top of this, their every viewing and \\ browsing habit is being closely monitored and meticulously recorded to be used for future marketing and \\ promotion.
}

There are little or no protections in place to prevent Australia's children from predatory marketing practices in the digital world.

This report highlights the worrying fact that digital marketing for alcohol, unhealthy food and gambling is reaching children at a very young age, affecting their attitudes, habits, consumption - and health. These consequences could be lifelong, determining the habits they form and the quality of life they can achieve.

Children can improve digital literacy. However, they simply cannot compete with the pernicious and ever-evolving tactics used by harmful industries to promote alcohol, unhealthy food and gambling.

Parents are facing an uphill battle to protect their children from harmful digital marketing due to a lack of regulation in Australia. Current industry-designed codes do little to protect children's rights in the digital space.

To support families in achieving good health and wellbeing, we need strong, evidence-based policies and government regulation to protect children from digital marketing by harmful industries.

As digital natives, Australia's children have the right to participate in the digital world without being exposed to harmful marketing.

It's time to put the health of Australian children before the profits of harmful industries.

\author{
Dr Sandro Demaio \\ Chief Executive Officer, VicHealth
}




\section{Contents}

Executive summary 4

1. Setting the scene 5

2. Marketing of harmful products 11

3. The digital marketing mix 13

4. The current (limited) protections in Australia 18

5. Responses from around the world 22

6. Conclusion: Time to act 25

References $\quad 26$

\section{Acknowledgements}

This report was prepared by VicHealth and co-contributors, led by Katy Cooper (independent consultant).

Co-contributors: Obesity Policy Coalition (OPC), Foundation for Alcohol Research and Education (FARE) and the Victorian Responsible Gambling Foundation (VRGF).

\section{Suggested citation}

VicHealth (2020), Under the radar: Harmful industries' digital marketing to Australian children. A report prepared by the Victorian Health Promotion Foundation, Melbourne.

https://doi.org/10.37309/2020.C1910 


\section{Executive summary}

Marketing of harmful products is ubiquitous in Australian society, with children exposed to a wide range of pervasive and often covert online marketing practices.

The younger generation are digital natives and derive significant value from their online interactions. Digital technology enables children to participate in education, to connect with others and access entertainment. This has become even more imperative during the coronavirus (COVID-19) lockdown.

However, children should be able to exercise their right to participate in the digital space without being exposed to the marketing of harmful products.

While empowering and building digital literacy among children and young people may increase their ability to recognise digital marketing, this is far from sufficient. Government policy must lead the way in ensuring that the digital environment protects children.

This report focuses on children up to and including the age of 17. It takes a collective approach to three harmful industries - industries that produce and promote products that are harmful to health and wellbeing:

- alcohol

- unhealthy food (processed foods high in sugar, fat and/or salt, and sugary drinks)

- gambling.

It addresses the health challenges that are fostered by these harmful industries, the diverse ways in which marketing targets children in the digital space, the limited ways in which this is currently regulated in Australia, and provides some examples of action in other countries.

Shared ways of working and tackling common commercial determinants of health can set the scene for a policy approach that upholds children's rights in the digital space.

Australia is falling behind in its regulation both of digital marketing of harmful products and children's privacy. It is time for government to protect the health and wellbeing of children over the profits of harmful industries. 


\section{Setting the scene}

The consumption of alcohol products, unhealthy food and gambling have serious health and economic consequences in Australia - and these habits are often formed in childhood. Our children are spending increasing amounts of time online, particularly on social media, in ways that are unseen and not understood by parents. These two issues can be brought together by a child-rights approach, which acknowledges that children have the right to participate online, but also that they have the right to be protected in the digital sphere from predatory marketing practices and privacy intrusions from harmful industries.

\section{Our children's health}

Habits formed around the consumption of alcohol products, unhealthy food and gambling among children are likely to continue into later life, leading to serious health consequences and economic costs.

Alcohol products can damage the brain as it develops, and they also contribute to the three leading causes of death in adolescents (unintentional injury, homicide and suicide). ${ }^{1}$ Starting to drink alcohol at an early age increases the risk of later physical and mental health conditions, including alcohol dependence. ${ }^{2}$

Unhealthy food is a strong driver of overweight and obesity. Children that are above a healthy weight are more likely to be overweight or obese as adults, increasing the risk of non-communicable diseases (NCDs) including many cancers, cardiovascular disease and type 2 diabetes, with early warning signs, such as pre-hypertension, sometimes appearing in childhood. ${ }^{3}$ After tobacco smoking, overweight/obesity and diet are the next leading risk factors for the disease burden in Australia. ${ }^{4}$

Gambling harm goes beyond financial losses to include mental health issues (including depression and suicide), lower work or school productivity, and crime. $^{5}$

Consumption of these harmful products is driven by multiple factors, so tackling them requires a combination of approaches. A critically important part of this is addressing their marketing - marketing that has, in the digital age, become persistent and insidious.

\section{Box 1}

\section{Coronavirus (COVID-19) lockdown impact on unhealthy behaviours}

On 11 March 2020 the World Health Organization (WHO) declared coronavirus (COVID-19) to be a pandemic. From March until the point at which this report was published in late 2020 , there have been restrictions put in place around Australia to prevent the spread of coronavirus. During this time some children intermittently attended school remotely and people were encouraged to stay at home. There are indications that some unhealthy behaviours increased during this period. A survey found that $43 \%$ of children reported consuming sugary drinks or treat foods on most days of the week. ${ }^{6}$ Reports suggest that since the start of 2020 , gambling spend has increased by $50 \%$ in Australia. ${ }^{7}$ Alcohol consumption increased among some population groups, ${ }^{8}$ with $12 \%$ of Australians drinking more during the lockdown. ${ }^{9}$ 


\section{Impact on health}

Statistics for Australia

Note: Gambling statistics are for Victoria only

Alcohol use
two years below the legal age. ${ }^{10}$

In 2017 18\% of children aged 12-17
- The average child consumes their first alcoholic drink at age 16.2 years, almost exceeded the adult guidelines for single occasion risky drinking. ${ }^{11}$

\section{Poor diet and obesity}

- Only 1 in 25 children (4.4\%) meet the guidelines for vegetable consumption. ${ }^{13}$

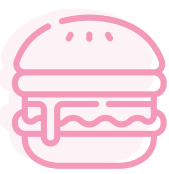
4-8-year-olds, 39\% among 9-13-year-
- $30 \%$ of 2-3-year-olds energy comes from unhealthy food, increasing to $38 \%$ among olds, and $41 \%$ of $14-18$-year-olds. ${ }^{14}$

- $42 \%$ of 5-14-year-olds consume sugar sweetened drinks or diet drinks at least once a week. ${ }^{15}$

- Almost one-quarter (24.9\%) of children aged $5-17$ years were overweight $(17 \%)$ or obese (8.1\%) in 2017-18. ${ }^{16}$

- There are significant inequities in obesity: overweight and obesity is more common among Aboriginal and Torres Strait Islander children aged 10-14 (37\% compared with $27 \%$ in non-Indigenous children). ${ }^{17}$

- The prevalence of overweight and obesity among children aged 5-14 was higher for those living in the lowest socioeconomic areas (27\%) compared to those living in the highest socioeconomic areas $(22 \%){ }^{18}$

- Children living in regional and remote areas are more likely to be overweight or obese (29\%) than those in major cities $(23 \%) .{ }^{19}$

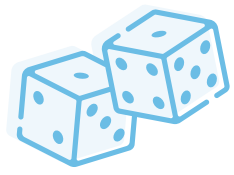

- $31 \%$ of Victorian secondary-school children have gambled in the past. ${ }^{23}$

- $1.4 \%$ of children aged $12-17$ meet the criteria for problem gambling. ${ }^{24}$

- Teenagers are four times more likely to develop gambling problems than adults. ${ }^{25}$

\section{Cost to Australia (annual)}

Across Australia the social costs of alcohol in 2010 was estimated to be $\$ 14.35$ billion, with the highest costs associated with productivity losses (42.1\%), traffic accidents (25.5\%) and the criminal justice system (20.6\%). ${ }^{12}$

Individual dietary risk factors cost up to $\$ 561$ million $^{20}$

Estimated productivity losses due to obesity are up to $\$ 14.9$ billion, ${ }^{21}$ with medical costs associated with overweight and obesity among 6-13-year-olds estimated at $\$ 43$ million. ${ }^{22}$

Cost of gambling problems to the Victorian Government $=\$ 1.145$ billion .

Together with financial, emotional/psychological, relationships/family, crime and productivity/work impacts, total cost $=\$ 6.97$ billion. ${ }^{26}$ 


\section{Our children online}

Use of digital technology among Australian children is ubiquitous from a young age.

- One-third of children aged 6-13 own a smartphone, with a further third having access to one $\mathrm{e}^{27}$

- 94\% of 14-17-year-old mobile owners have a smartphone 28

- $98 \%$ of 15-17-year-olds are internet users. ${ }^{29}$

Teenagers spend a significant amount of time online, including an estimated 3.5 hours a day on social media in 2017. ${ }^{30}$

Social media platforms of choice among Australian children are shown in the table: ${ }^{31}$

TikTok is the most recent addition - for which data on use is not yet available in Australia, but a recent report suggests that up to a third of users in the United States are classified as aged 14 or younger. ${ }^{32}$

Children are also keen gamers $-81 \%$ of children aged 5-14 play video games (the second most likely age group to do so) and children under 18 make up $22 \%$ of all gamers in Australia. ${ }^{33}$

During the coronavirus pandemic, a new survey found that $51 \%$ of children increased their time on screens and digital media for entertainment, with $77 \%$ of school-aged children spending more than 3 hours on screens each day. ${ }^{34}$ This included online gaming, social media and watching video content.

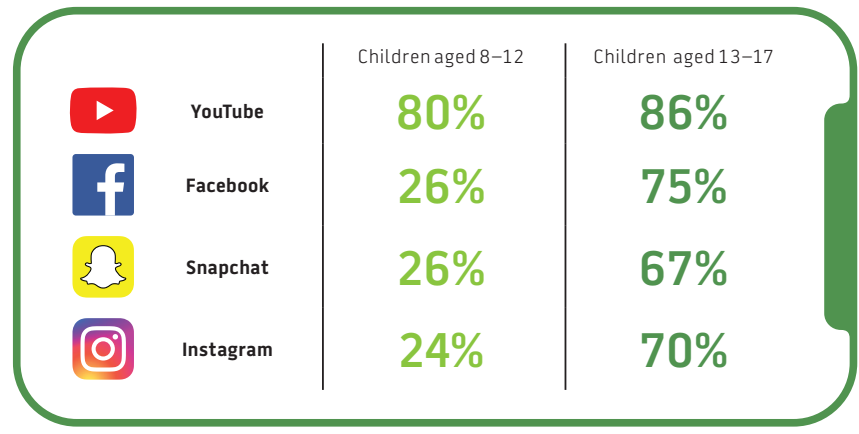

Source: Office of the eSafety Commissioner 2018, "Young people and social media usage', https://www.esafety.gov.au/about-us/research/ youth-digital-dangers/social-media-usage

\section{Box 2}

\section{What is digital marketing?}

Digital marketing is 'promotional activity, delivered through a digital medium, that seeks to maximize impact through creative and/or analytical methods'. ${ }^{35}$ This can be done in a wide variety of ways, either explicitly through brand advertisements or implicitly through sharing within children's own social networks, online games, or the use of 'influencers' (such as YouTube or Instagram stars). Together these create a highly immersive environment, one to which children's attention is consistently attracted. Users are also increasingly tracked by the platforms (Google, Instagram, Facebook, YouTube, TikTok etc.), which enables the marketing to be individually targeted - and, as parents and children have quite different online experiences, this makes it harder for even the most attentive and engaged parent to understand or monitor their children's online exposure. 


\section{A child-rights approach}

The digital environment is part of all our lives: we use it to find information, to have fun, to connect with friends, to learn, and to take part in society. Children need - and have the right - to be part of this environment. However, there is a tension between commercial interests and children's wellbeing: the pervasive digital environment exposes children to marketing of harmful products that can lead to short and long-term harm.

The rights of the child are at the heart of understanding why action is required on digital marketing. The United Nations Convention on the Rights of the Child (CRC), ${ }^{36}$ to which Australia and almost every other country in the world is a signatory, sets out the range of rights that children have, all of which require the 'best interests of the child' to be prioritised. Our children have:

- Participation rights - such as freedom of association and the freedom to access information.

- Protection rights - such as the right to privacy (see Box 3), the right to health and the right to be free from economic exploitation. ${ }^{37}$

Protection rights need to be appropriately balanced with children's ability to benefit from online connectivity. Children should be free to participate in the digital environment without exposure to marketing of harmful products, and governments should prioritise children's health above the profits of harmful industries. ${ }^{38}$

\section{"There are laws to protect children in the real world - film ratings, car seats, age restrictions on drinking and smoking. We need our laws to protect children in the digital world, too"}

- Elizabeth Denham, Information Commissioner, UK ${ }^{39}$

\section{Box 3}

\section{Privacy and children's data}

Digital marketing is increasingly sophisticated, relying on the collection and use of children's personal data to target advertising, including their responses, preferences, emotions and location. ${ }^{40}$

This information is critical for harmful industries in developing marketing strategies, both to understand ways in which to engage children in the short term, and to hook them in as long-term consumers into adulthood. ${ }^{41}$ This data-mining is extremely extensive: one estimate suggests that 72 million data points will have been collected on each child by the age of 13 - and this is used to build a profile of each user so that marketing can be used to most effectively attract each child. ${ }^{42}$

In 2018 Facebook was found to have flagged 740,000 children as being interested in gambling and a further 940,000 children as being interested in alcohol products. ${ }^{43}$ This 'interest' is based on monitoring of the children's activity and is automatically generated - and can then be used to target messaging at the children - although Facebook says that it works with regulators to avoid ads being targeted at this age group.

All users of the internet are subject to the collection of personal data - but children's data rights need to be protected. Even adults struggle to understand the ramifications of providing their own data, and providing consent on behalf of a child is even more problematic. ${ }^{44}$ The vulnerability of children means that privacy should be tighter for children than for adults - but in Australia (unlike in some other parts of the world) this is not the case. The collection of personal data has privacy repercussions for children that go far beyond the short-term marketing of harmful products, potentially affecting issues such as future credit scores and job eligibility. ${ }^{45}$ 
Digital marketing of harmful products infringes on these rights by exploiting children's cognitive development. ${ }^{46}$ Children, and often even adults, are not always able to recognise the difference between marketing and entertainment, particularly when this marketing is not disclosed or comes from trusted sources such as their peers or social media influencers. Children are therefore unable to give informed consent to receiving such marketing, even when a consent option is available.

\section{Age matters}

The Convention on the Rights of the Child and the WHO Commission to End Childhood Obesity $(\mathrm{ECHO})^{47}$ are both clear that children should receive particular protection up to the age of 18. Children develop at very different speeds, but up to the age of 18 their cognitive capabilities are understood to be still developing.

As children enter their adolescent years and become independent, they are particularly susceptible to influence from their peers, including through social media, and may be more impulsive. ${ }^{48}$ The older the age that is set for restrictions, the more protection it provides for younger children, who are likely to admire and try to copy older children. ${ }^{49}$

The current regulations in place in Australia to protect children from harmful digital marketing vary across industries and do not offer sufficient protection to children under 18 years. While there have been some attempts to prevent children from being targeted by alcohol and gambling marketing, for example, age-verification on owned websites (see Box 4), this is not sufficient and does not apply to the innovative ways that marketing now occurs in the digital space.

\section{Alcohol}

Although children aged under 18 are not supposed to be targeted to alcohol marketing, the lack of effective protections means that children are exposed in the digital space. For instance, a recent study of e-sports gamers and viewers aged 16-34 found that many were exposed to undisclosed alcohol marketing via livestreaming events and in-game rewards (e.g. 'loot-boxes'). ${ }^{50}$ Similarly, research has shown that many children and young people are exposed to alcohol product promotion via the influencers they follow on social media platforms. ${ }^{51}$ There is also evidence from the ABAC Responsible Alcohol Marketing Code's own adjudications that children watching cartoons on YouTube are being targeted by an online alcohol delivery service. ${ }^{52}$

\section{Unhealthy food}

Australian children have the least protection from unhealthy food marketing. The current codes designed by the food and advertising industries (see section 4) allow unhealthy food companies to target children through interactive marketing on social media platforms (for example through paid marketing or through pages, accounts and channels owned by food brands) and through games and competitions (on social media, websites or brand-owned mobile applications). Children are engaging with digital marketing from unhealthy food companies on a daily basis, allowing marketers to capitalise on the users' social networks and tailor marketing according to personal interests. Australian 10-16-year-olds watching foodbranded video content on YouTube and seeing food brands advertised online have been shown to have significantly higher consumption of unhealthy food and drinks. ${ }^{53}$ Children as young as 7 who are exposed to unhealthy snacks via rewarded video advertising within 'advergames' have been shown to have significantly higher brand loyalty to those foods. ${ }^{54}$ 


\section{Gambling}

While current regulation prohibits gambling companies from directly marketing to children under 18 years, social media, online gaming and e-sports also present mechanisms through which children can be exposed to gambling content, promotions and advertising. For instance, social casino games can be advertised and promoted online, unlike gambling products in which real money is exchanged. ${ }^{55}$ Research has shown that advertising for social casino games often use imagery that is known to appeal to young people, including the use of bright colours and cartoon animal characters. ${ }^{56}$ of the social casino games available for download on Android, $97.7 \%$ have an age rating of $12+$ or younger. ${ }^{57}$

This all highlights the need to have consistent approaches to prevent children under 18 from being exposed to digital marketing of harmful products. Approaches to ensure that children are protected from being exposed to harmful digital marketing need to be consistent across these industries and encompass more than just individual platforms and browsers. They should also recognise the interaction between live events and sharing of content digitally among online networks.

\section{Box 4}

\section{Age-verification}

Age-verification measures are used to restrict children's access to inappropriate digital content on alcohol and gambling websites. Some social media platforms have theoretical restrictions around children using their sites. For example, Facebook permits children to join from the age of 13 , Twitch allows children from 13 years to join - but also requires that the platform be used with adult supervision up to the age of 18 , and children under 13 years on TikTok can only use a walled-off mode within the app, which does not allow them to share personal information or videos.

Many age-verification efforts on websites are minimal: simply clicking a button to state that the user is over a specific age or entering a birth date that can be falsified, with no accompanying verification process. From that point onward, the platform will deliver age-appropriate marketing.

However, even if the age provided is accurate, current age-verification methods do not protect children from being exposed to harmful products that are promoted by influencers or peer-topeer content sharing on social media. Harmful industries are increasingly investing in these forms of digital marketing as they have greater value and engagement (see section 3). 


\section{Marketing of harmful products}

\begin{abstract}
Digital marketing across harmful industries is covert and pernicious, and spending is rapidly increasing. Digital marketing reaches children at too young an age, and there is evidence that it affects their attitudes, habits and consumption, and their health in later life. Children are digital natives but marketing naïfs, and they are insufficiently protected: the codes to protect them are industry-designed and do not have the best interests of children at heart.
\end{abstract}

\section{Harmful industries marketing: a joined-up approach}

The digital environment within which children encounter alcohol, unhealthy food and gambling marketing is complex and pervasive. The effect of marketing is cumulative: repeated exposure to marketing of harmful products leads to increased recall and recognition of brands by children, and ultimately increased purchase and consumption of these products, ${ }^{58}$ whether through 'pester power' for unhealthy food or through purchase by teenagers themselves who have gained their independence. Children are more susceptible to marketing messages the younger they are, ${ }^{59}$ and their exposure to harmful products and behaviours in the digital environment helps to drive new and harmful social norms. ${ }^{60}$

\section{Digital marketing reaches children at too young an age, it affects their attitudes, habits and consumption, and their health in later life}

\begin{abstract}
Taking a shared approach strengthens the message that the regulatory response to digital marketing across the board is piecemeal and 'self-regulatory'. Codes are designed, administered and enforced by industry, and prioritise the profits of industry, not the rights or best interests of the child, and evaluation of such codes shows that they are largely ineffective. ${ }^{61}$ Looking at digital marketing across alcohol, unhealthy food and gambling not only allows for shared learning, but also for shared concern at the way in which harmful industries market their harmful products directly to children to establish brand loyalty and lifelong consumption.
\end{abstract}

\section{The impact of digital marketing}

Alcohol $\begin{aligned} & \text { Exposure to alcohol marketing } \\ & \text { increases young people's } \\ & \text { consumption }{ }^{62} \text { and increases the } \\ & \text { chances that they will start to drink } \\ & \text { at a younger age. }{ }^{63}\end{aligned}$
Children's participation in alcohol marketing is associated with riskier drinking patterns. ${ }^{64}$

\section{Unhealthy food}

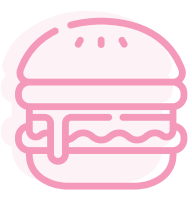

- Online engagement with food brands on social media is associated with increased consumption of unhealthy food among children aged $10-16 .{ }^{65}$

- $38 \%$ of YouTube ads are for food and beverages - the majority of which are for unhealthy products. ${ }^{66}$
- A quarter of celebrity endorsements of products on social media are for unhealthy foods - and children are more likely to share these posts than posts for healthier products. ${ }^{67}$

\section{Gambling}

- A study of some Australian children aged 11 - 16 years found more than half (55\%) recall seeing gambling

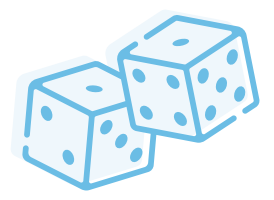
advertisements on social media. ${ }^{68}$

- More than one-third of 12-17-yearolds reported being aware of gambling advertisements or promotions on websites (34.3\%) and social networking sites (37.6\%) in the past 30 days. ${ }^{69}$
- $75 \%$ of Victorian 8-16 year olds can recall the brand name of at least one sports betting company. ${ }^{70}$

- Among those who had gambled in the past 30 days, 54\% reported being aware of gambling advertising/ promotions on social networking sites during that period. ${ }^{71}$ 


\section{The effect of marketing is cumulative: repeated exposure to marketing of harmful products leads to increased recall and recognition of brands by children, and ultimately increased purchase and consumption of these products}

Harmful companies and brands are in constant competition to get online engagement with products - platforms such as Google and Facebook are free for users because we pay for them with our attention: data on our interests is monetised through the advertising that we see. This is highly persuasive, across a whole range of platforms ${ }^{72}$ and in the community.

In 2017, The Australian reported that Facebook told advertisers that it had a database that included 1.9 million high-schoolers, that could monitor young Australians in real time and identify their mood and when they felt 'overwhelmed', 'anxious' or 'a failure'. ${ }^{73}$

Companies are also able to target marginalised communities beyond children: people with disabilities, people with addiction or mental health challenges, culturally and linguistically diverse communities, Aboriginal and Torres Strait Islander communities, or young LGBTQI people.

Companies are also finding new ways to use digital media. For example, Sportsbet uploaded a branded filter to Snapchat to coincide with their sponsorship of the 2020 Australian Football League (AFL) and National Rugby League (NRL) 2020 grand finals, an app primarily used by children and young people.

\section{Box 5}

\section{An acceleration of harmful marketing during coronavirus (COVID-19)}

Harmful industries have pivoted in response to coronavirus and focused in on digital marketing to capitalise from lockdown in Australia. During a 1-hour period of monitoring sponsored alcohol marketing on an adult's Facebook and Instagram accounts, 107 alcohol advertisements were displayed: an average of one ad every 35 seconds. ${ }^{74}$ While not explicitly aimed at children, this volume of advertising is concerning. Similarly, fast-food companies in Australia have been at the forefront of this opportunistic marketing, with companies providing an expanded range of products including essential items such as bread and milk, and encouraging 'comfort eating'. ${ }^{75}$

In September 2020, The NCD Alliance and SPECTRUM research consortium published Signalling Virtue, Promoting Harm: Unhealthy Commodity Industries and COVID-19. The report used crowdsourcing to find hundreds of examples from over 90 countries around the world, demonstrating how the alcohol, unhealthy food and gambling industries have leveraged the coronavirus pandemic to market their products. ${ }^{76}$ 


\section{The digital marketing mix}

Digital marketing is rapidly growing in Australia, and children are exposed to an increasing range of marketing activities online, a mix of explicit advertising and much more subtle techniques, which are harder to recognise. These include brand-owned content, influencer posts on social media and content shared by friends, and are offered in a wide range of contexts - on social media, mobile apps, digital out-of-home advertising, and watching video content online (including sports and e-sports). Unlike other forms of advertising (outdoor, television, radio, in-venue), digital marketing is ephemeral and uniquely unavailable to scrutiny. The environment within which children are using digital products should be protective - but at the moment it is failing to be so.

\section{Types of marketing}

Digital marketing comes in three types outlined below, with some formats using a combination of these different forms of marketing to reach children:

- Owned marketing is owned by brands, is unique to them, and appears on companies' own websites or social media pages. This is known as 'owned' media because it is under the direct control of the brands.

- Paid marketing is paid for by brands and appears on other websites and platforms (including 'sponsored' advertising on social media). The systems behind this form of advertising are often extremely complex (see Box 6) and are proving illusive to regulate.

- Earned marketing is shared online and only happens if consumers are sufficiently interested to interact with it. This is created and shared by consumers themselves on platforms such as Instagram, Snapchat and TikTok, rather than brands having to do the work of disseminating branded content.

\section{Box 6}

\section{Monitoring children's exposure to digital marketing: a challenge}

Monitoring and researching children's exposure to digital marketing poses new challenges both because of its complexity but also because - short of looking over a child's shoulder - it is impossible to be certain what they see online. There are ways to track children's use of the internet in a research setting, such as screen capture, mechanisms of action (such as engagement with 'likes') or even eye tracking (that can capture the fixation and duration of a child's attention), although these all require strong ethical frameworks and clear consent from child and carer. ${ }^{77}$ Avatars that mimic the behaviour of a child and other automated tools can also be used. But all of these struggle to reach an understanding of what really gets children's attention and what information they retain (which is the aim of marketing in the 'attention economy'). In addition, the platforms themselves are constantly developing - introducing new features and settings - which makes it challenging to keep up and for any research to be consistent or meaning ful once it reaches publication. 


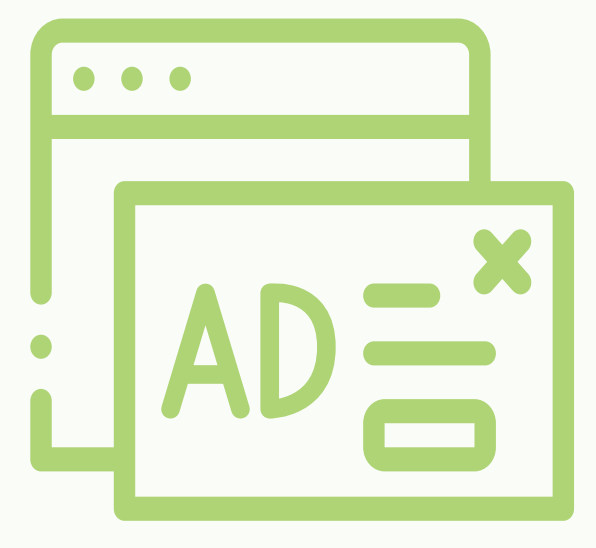

\section{Third-party websites}

This is marketing that pops up on websites not owned by the brands - for example, sponsored posts on YouTube videos, sponsored ads on Facebook, or advertisements on Google or other website such as news media. See Box 7 for details of how these ads are targeted to reach children.

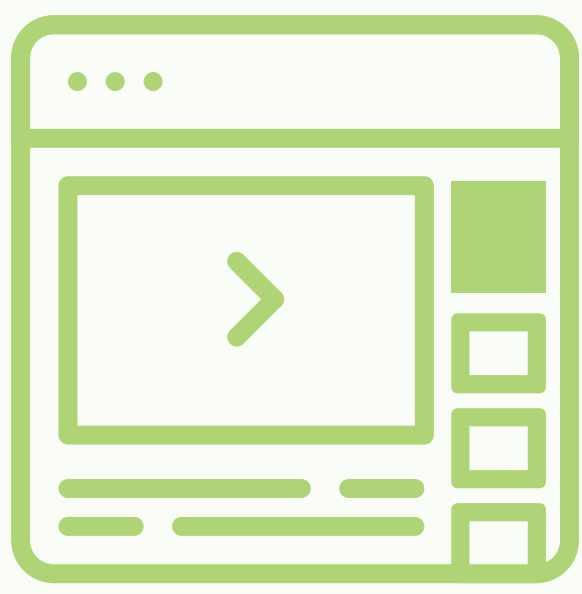

\section{Branded sites}

These are the most identifiable forms of marketing: the companies' own websites and their branded pages on social media. Social media platforms actively encourage users to interact outside their circle of friends, making it more likely that they will discover branded content.

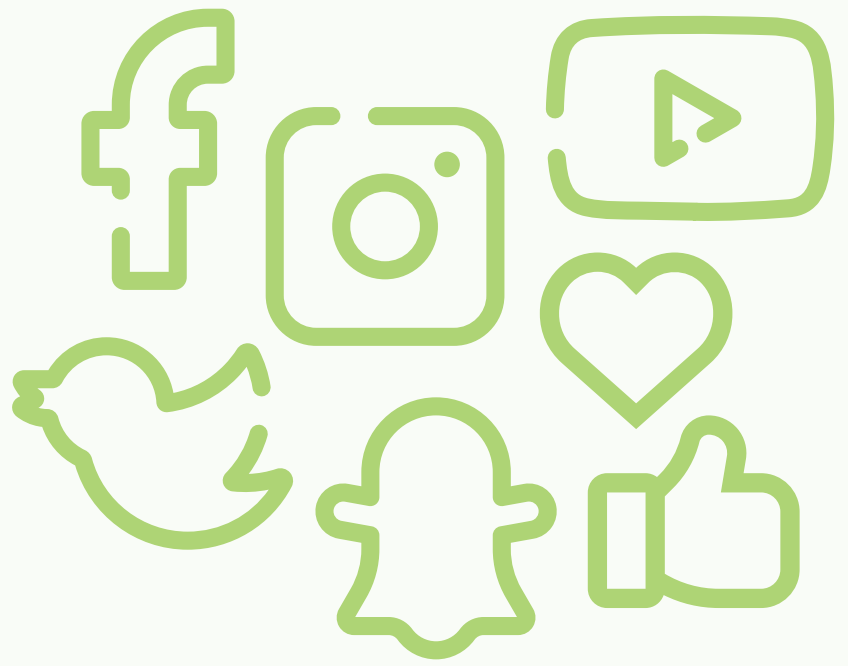

\section{Social media sharing}

Children (and adults) listen to and trust their friends and people they follow on social media - and the brands know this. Peer endorsement - through clicks, likes and sharing photos - blurs the boundaries between marketing and peer activities.

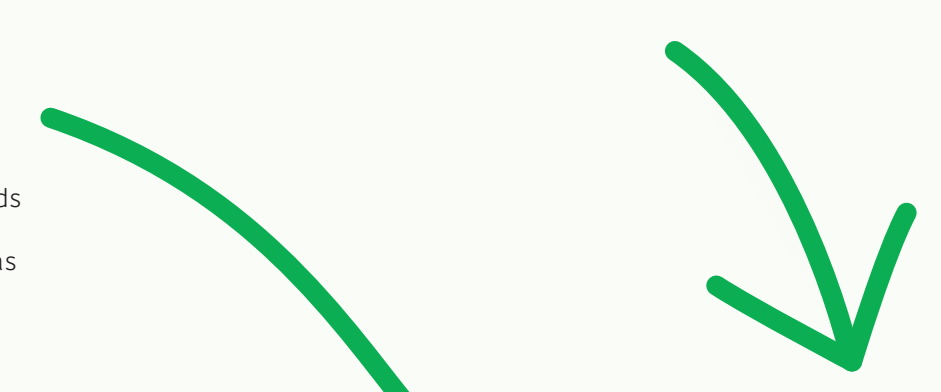




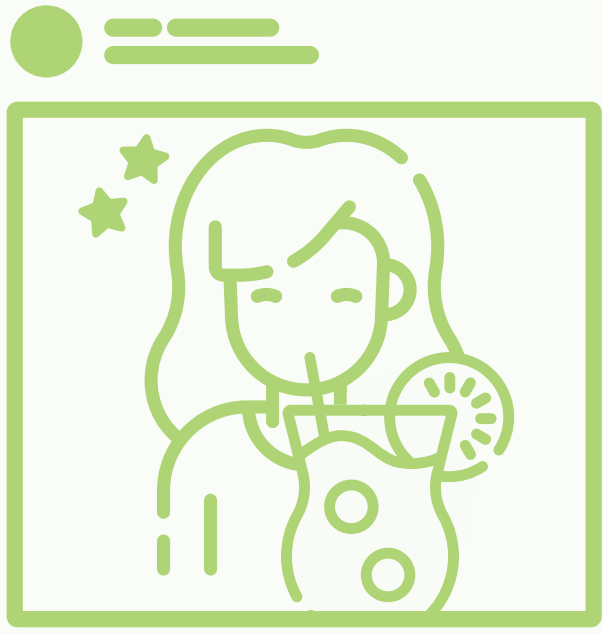

\section{Influencers}

Harmful industries are increasingly using influencers to promote products to their digital community. Stars of social media platforms, particularly Instagram, YouTube and, increasingly, gamers on Twitch - are regarded as authentic, relatable and approachable, so when they make endorsements or mention products, children are more likely to take note
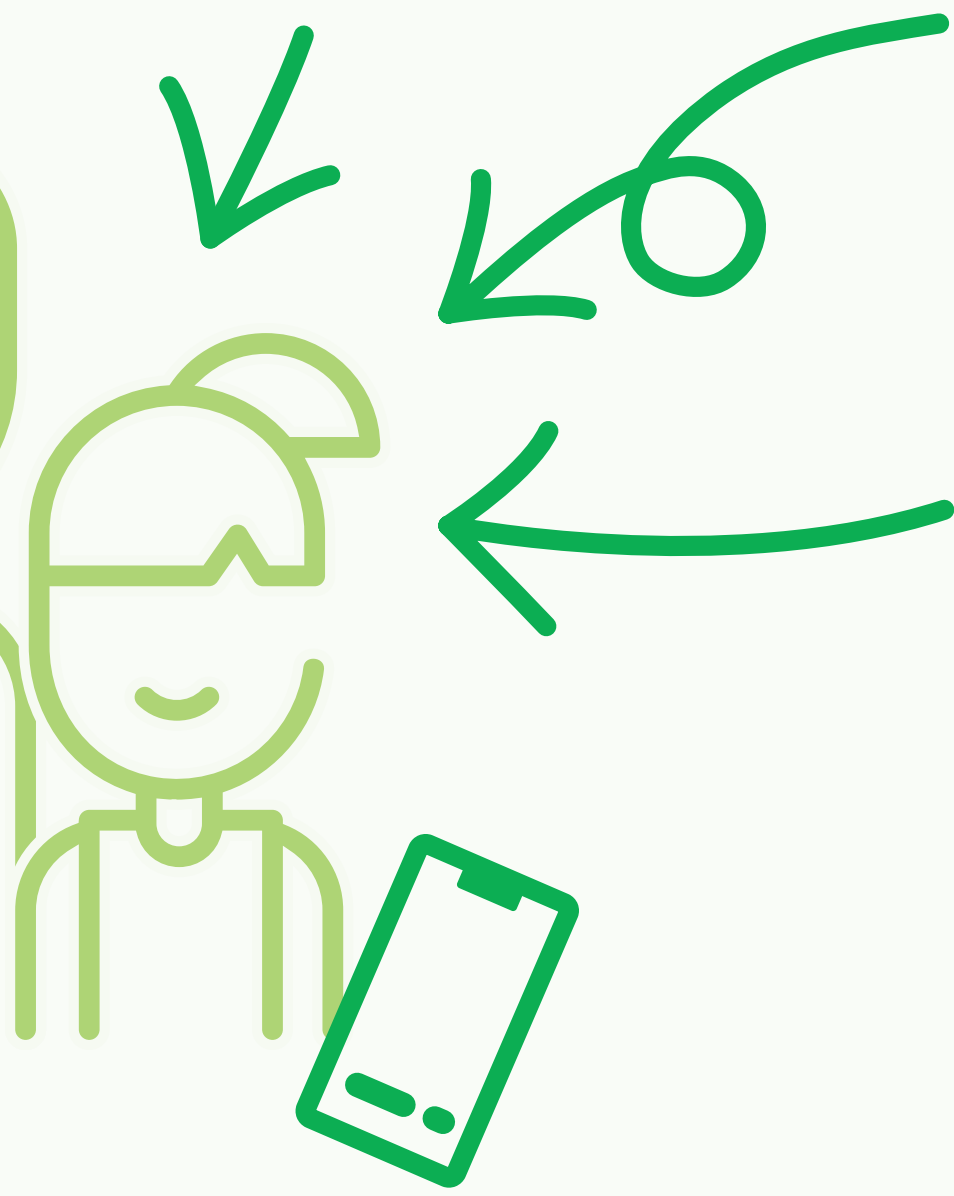

\section{Games and challenges}

Harmful industries are increasingly using gamification such as challenges or competitions initiated by influencers to make them go viral. Children are also nowadays able to access simulated gambling in games or play games that are monetised, which can normalise the behaviour and act as a gateway to gambling.

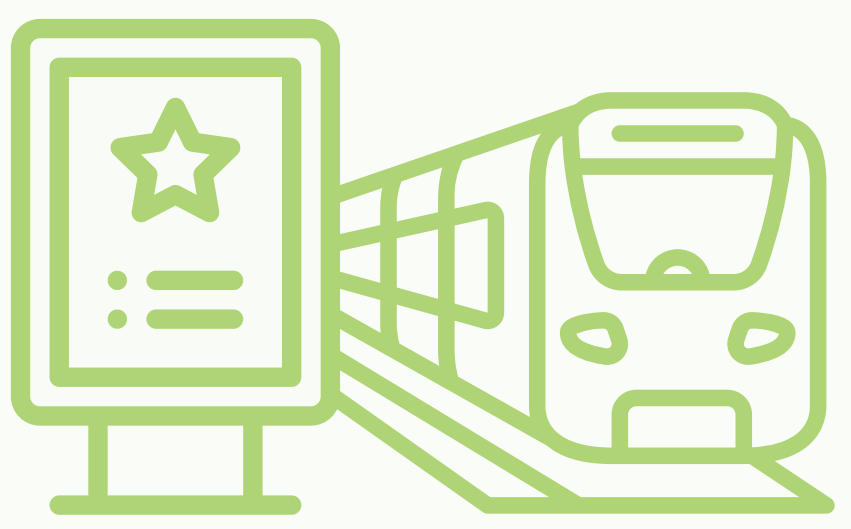

\section{Digital out-of-home}

A form of marketing that is coming over the horizon is digital out-ofhome advertising. This is now capable of taking data from mobile phones and delivering targeted advertising on digital displays for each individual who walks past - for example, at bus stops and train stations. 


\section{Branded sites}

These are the most identifiable forms of marketing: the companies' own websites and their branded pages on social media. They can be age-verified to some extent but - as Box 4 noted - this is easy for children to get around. Social media platforms actively encourage users to interact outside their circle of friends, making it more likely that they will discover branded content. There is also an added problem that sites may not state the name of the brand but clearly be linked with a brand, which means that advertising to children can fall through a gap.

\section{Third-party websites}

This is marketing that pops up on websites not owned by the brands - for example, sponsored posts on YouTube videos, sponsored ads on Facebook, or advertisements on Google or other website such as news media. See Box 7 for details of how these ads are targeted to reach children.

\section{Box 7}

\section{Targeted ad delivery}

Targeted, automated systems of delivery of advertisements (known as 'programmatic' advertising) gives brands the ability to use data drawn from previous online browsing and activity history to target children with ads that will be more relevant to their interests. This system is cheap and is increasingly being used in Australia, where an expected $69 \%$ of digital advertising will be programmatic in $2020^{78}$ - but this is still well behind countries such as the United Kingdom, where over $90 \%$ of online ad spend takes this form. ${ }^{79}$

\section{Social media sharing}

Children (and adults) listen to and trust their friends and people they follow on social media - and the brands know this. Peer endorsement - through clicks, likes and sharing photos - blurs the boundaries between marketing and peer activities. The materials shared may be branded advertising that extends the reach of campaigns to a wider audience, or content that has been created by users themselves. The latter is more impactful than marketing paid for by the brands. ${ }^{80}$ If it is clear that something is an ad on social media, it will receive fewer likes. ${ }^{81}$

\section{Influencers}

Influencer marketing is anticipated to be worth US $\$ 15$ billion worldwide by $2022 .{ }^{82}$ Harmful industries are increasingly using influencers to promote products to their digital community. Stars of social media platforms, particularly Instagram, YouTube and, increasingly, gamers on Twitch - are regarded as authentic, relatable and approachable, so when they make endorsements or mention products, children are more likely to take note. It is impossible to assess what percentage of followers are children, but many influencers have substantial followings. ${ }^{83} 45 \%$ of Gen Z (born 1997-2012) in Australia follow more than 10 influencers and more than one in 10 follows more than 50 influencers. ${ }^{84}$ Many influencers endorse or mention harmful brands: a survey of 380 videos from two influencers found 3,500 food and beverage cues. ${ }^{85}$

\section{A particular concern is 'astroturfing', whereby influencers are commercially sponsored but give the impression of making a casual recommendation of a brand.}

This is paid-for advertising, but with little or no indication that this is the case. An analysis of Australia's top 70 instagram influencers found that $73 \%$ featured alcohol products in their posts, yet only $26 \%$ disclosed that it was a paid promotion with an alcohol brand. ${ }^{86}$ 


\section{Games and challenges}

It is often difficult to distinguish between games and marketing, such as advergames and branded activities designed to entertain children. Harmful industries are increasingly using gamification such as challenges or competitions initiated by influencers to make them go viral, for example Hungry Jack's \#TropicLikeltsHot. Unhealthy food companies are also using activity and game apps such as the McDonald's Happy Meal app and Magic Kinder app, instead of children's websites as they have in the past. Children are also nowadays able to access simulated gambling in games, which can normalise the behaviour and act as a gateway to gambling. ${ }^{92}$ Video games are increasingly becoming monetised in ways that enable unregulated gambling on external platforms, and there has been a significant rise in the presence of gambling within competitive gaming events and online broadcasts. ${ }^{93}$

\section{Digital out-of-home}

Currently, over $90 \%$ of us are exposed to outdoor advertising at least once a day. ${ }^{94}$ Children are constantly exposed to unhealthy food marketing to and from school ${ }^{95}$ and on public transport. ${ }^{96} \mathrm{~A}$ form of marketing that is coming over the horizon is digital out-of-home advertising. This is now capable of taking data from mobile phones and delivering targeted advertising on digital displays for each individual who walks past - for example, at bus stops and train stations. This is not yet commonplace in Australia, but in other markets such as in the UK it is increasingly being used. ${ }^{97}$

\section{Box 8}

\section{Advertising on Twitch}

Twitch is the world's largest live-streaming platform, owned by Amazon, primarily used for streaming. Twitch attracts a young audience, with the platform estimating that the average user is aged just $21 .{ }^{87}$ With an estimated 1.4 million concurrent viewers on average ${ }^{88}$ it is a highly 'sticky' social media platform, meaning that users spend significant amounts of time on it. In 2018, Australian users were spending an estimated 1 hour 45 minutes on Twitch each day, ${ }^{89}$ and time on the platform jumped by almost a quarter globally under COVID-19 lockdown. ${ }^{90} \mathrm{~A}$ recent study found that sugary drinks are one of the most frequently mentioned products in chat rooms where users connect with each other. ${ }^{91}$ 


\section{The current (limited) protections in Australia}

The current limited framework governing digital advertising of harmful products to children is industry designed and industry led. These codes are insufficiently rigorous and lack enforcement and sanction powers to protect children from harmful marketing.

\section{Regulation or self-regulation?}

There is state and territory legislation that prohibits retailers from selling alcohol to children under 18 years, and federal legislation that sets an age limit of 18 years for participation in gambling activities, but the regulatory context restricting marketing for these activities is much less clear. 'Self-regulatory' industry codes* govern the advertising of alcohol, gambling and unhealthy food to children, but the evidence suggests that these are not a sufficient protection to ensure that harmful industries do not market their products to children. Self-regulation by harmful industries is inadequate and inappropriate as there are clear conflicts of interest, whether in unhealthy food, alcohol or gambling. Comprehensive regulation is also needed to prevent a 'squeezed balloon effect' in which marketing migrates to unregulated channels as regulation is introduced.

\section{Industry-wide mechanisms}

The Australian Association of National Advertisers (AANA) has a self-regulatory system that covers all advertising, including the three harmful industries that are the focus of this report:

\section{- AANA Children's Advertising Code: ${ }^{98}$ This Code is very} broad and does very little to limit children's exposure to marketing for unhealthy food, alcohol and gambling. The Code generally applies to marketing that is directed primarily to children and is for products targeted to children. It contains broad principles based on concepts of prevailing community standards, and covers issues including factual presentation, parental authority, social values, competitions, the use of popular personalities and premiums. It contains a restriction about marketing alcohol directly to children and a requirement that marketing to children for food and beverages '...must neither encourage nor promote an inactive lifestyle or unhealthy eating or drinking habits'. In practice, this does not prevent unhealthy food marketing to children, as simply promoting unhealthy food to children has been found not to be enough to establish that an advertisement encourages or promotes unhealthy eating or drinking habits. It is often argued that eating a single unhealthy product 'occasionally' or 'in small amounts' can be part of a balanced healthy diet.

\section{- AANA Wagering Advertising and Marketing} Communications Code: ${ }^{99}$ This is a self-regulatory communication code on wagering advertising and marketing that covers Australian licensed wagering operators, such as TABs and online bookmakers. The Australian Communications and Media Authority (ACMA) approves the code, while complaints about breaches of the code are determined by the Ad Standards Community Panel, which forms part of the self-regulatory structure.

In addition, the Australian Influencer Marketing Council (AIMCO) published a new set of guidelines in July 2020 outlining standards for influencers to clearly disclose when they are promoting a product. ${ }^{100}$ It is not yet evident what effect, if any, these guidelines will have on the actions of influencers. However, it is anticipated that this may reduce 'astroturfing' and casual recommendations of harmful products by influencers.
* Often referred to as 'self-regulatory codes', we here choose to use 'industry codes' as being more reflective of their voluntary nature and the lack of real enforcement embedded within them. 


\section{Alcohol}

Since 1997, the core pillar of alcohol advertising in Australia has been the ABAC Responsible Alcohol Marketing Code. ${ }^{101}$ Subscribing to the Code is voluntary and there are many well-documented ways in which it has failed adequately to protect children.

The ABAC sets out a raft of standards that include:

- a ban on advertising that has 'strong or evident appeal to children', whether or not they are the intended audience

- a prohibition on the depiction of children and also of adults who appear to be under the age of 25

- rules to prevent advertising from being targeted at children based on its placement in media. For example, TV shows or other media with less than a specified proportion of underage viewers (usually around 25-30\%) are exempt from restrictions

- the use of age-verification where this is available. However, it does not require advertising to be restricted only to platforms where verification is present - and most age-verification efforts can be easily circumvented by children (Box 4).

There are mechanisms to bring a public complaint about non-compliance with the ABAC, which are heard by the ABAC Adjudication Panel. However, even when a complaint is upheld (at which point the offender has 5 days in which it 'must' take down or amend the advertisement), no sanctions are available even in the case of serious and ongoing noncompliance, and in practice the marketing may remain online. ${ }^{102}$

\section{Box 9}

\section{Complaints mechanisms: not fit for purpose?}

In the past, when television and radio were our main forms of media and everyone was exposed to the same advertising, it was more straightforward to understand what children saw, and complain appropriately. But parents do not know what their children see online, and marketing may be so deeply embedded in social media that neither child nor parent may realise that they are viewing marketing - and this makes it much less likely that complaints will be lodged. This is reflected in the complaints made to the Ad Standards Community Panel, where only $16 \%$ of complaints to the AANA are for online advertising. ${ }^{104}$ There are increasing calls for a fully independent complaints mechanism overseen by a government body, with monitoring and enforcement power across all the harmful commodities. 


\section{Unhealthy food}

There is currently no government regulation in Australia to protect children from unhealthy food marketing on digital media. In addition to the Children's Advertising Code, which applies to food and beverage marketing as well as to marketing for other products, the food and advertising industries have developed their own codes that purport to restrict unhealthy food marketing to children across different media types, including most forms of digital media. In practice, these codes do little to protect children from unhealthy food marketing and are particularly ineffective in the way they apply to digital marketing.

The Australian Food and Grocery Council has developed two industry codes applying to unhealthy food marketing to children: the Quick Service Restaurant Initiative for Responsible Advertising and Marketing to Children (QSRI) for fast-food chains, and the Responsible Children's Marketing Initiative (RCMI) for other types of food manufacturers and retailers. These codes are now managed by the AANA. The AANA also developed a Food and Beverages Advertising Code, and requires advertisers to comply with the RCMI and QSRI, where applicable.**

\section{There is currently no government regulation in Australia to protect children from unhealthy food marketing on digital media}

Overall, the industry codes do not protect children from digital marketing of unhealthy food. The main reasons for this failure are: ${ }^{105}$

\section{- the codes only restrict marketing that is 'directed} primarily to children', and this is defined and interpreted very narrowly. For example, one test that can be applied under the RCMI and QSRI is whether children make up at least $35 \%$ of the audience. This test has been applied to popular social media sites, including Facebook, Instagram and Snapchat, with these found not to meet the test ${ }^{106}$
- the codes do not protect older children. The RCMI only applies to children under 12, the QSRI only applies to children under 14 and the relevant parts of the Food and Beverages Advertising Code (as well as the Children's Advertising Code) only apply to children 14 or younger

- the RCMI and QSRI use inappropriate definitions of 'healthier' foods that can be advertised to children. The RCMI, for example, allows companies to decide what they consider a 'healthier' choice. In many cases, companies choose systems that enable marketing of unhealthy foods that are not recommended by the Australian Dietary Guidelines, such as high-sugar breakfast cereals, biscuits and ice creams

- the codes do not protect children from brand marketing. For example, an unhealthy food company can still promote its brand to children if it does not promote unhealthy food directly

- there is no effective mechanism to ensure that companies comply with the codes, and there are no financial penalties when a code is breached. The complaintshandling process can also be slow, with the consequence, for example, that the marketing campaign may be finished before a complaint is decided

\section{Gambling}

Online gambling and attendant advertising are regulated under the Interactive Gambling Act 2001. ${ }^{107}$ Under the Act, online gambling is prohibited, but exceptions are made for sports betting, race wagering and purchasing lottery tickets from providers licensed in Australia. This means it is illegal to provide online casino games, such as roulette or poker, to Australian residents. It is also illegal for a provider not licensed in Australia to provide sports betting and race wagering to Australian residents.

Similarly, illegal gambling providers cannot advertise prohibited activities under the Act. However, Australian licensed providers of sports betting, race wagering and online lotto can be advertised, subject to certain restrictions. 
For instance, rules approved by the ACMA restrict gambling advertisements being shown during live sport on free TV, pay TV and radio between $5 \mathrm{am}$ and $8.30 \mathrm{pm}$ - this time restriction is the same for sport being streamed live online. ${ }^{108}$ The ban applies from 5 minutes before the live sports event commences, during the event and for 5 minutes after the event has concluded - but this does not cover the pregame build-up, when there are many advertisements shown, which children may be exposed to. After 8.30pm, gambling advertisements can be shown.

ACMA is also responsible for prohibiting gambling advertisements during the online streaming of live sport. The Broadcasting Services (Online Content Service Provider Rules) 2018 prohibits gambling advertising during live sport that is streamed online between $5 \mathrm{am}$ and $8.30 \mathrm{pm}$. These rules bring online services in line with television and radio broadcasting services.

There are significant concerns that the existing regulatory framework is insufficient to protect children from being exposed to gambling advertising. Research has demonstrated that children and teenagers are likely to be viewing content on television or online past $8.30 \mathrm{pm}$, and so may still be exposed to gambling advertising. ${ }^{109}$ Similarly, it is unclear whether these protections apply to social media sites such as Facebook, Instagram or YouTube. ${ }^{110}$ Although internet providers may block advertising for prohibited gambling activities, they are not liable in the event that they fail to do so. ${ }^{111}$

Lastly, existing regulation fails to account for the marketing of gambling products and gambling-like content through other means. Social casino games feature gambling-like content and concepts and can be advertised to children online, which can act as a gateway to gambling. Online gaming influencers, with audiences reaching into the millions, have also been found promoting gambling and betting tips either contained in or related to online video games. ${ }^{112}$

Recent research commissioned by the Australian Department of Communications found that online games that involve real financial tranasactions, including via simulated gambling or loot boxes, are seen as gambling. ${ }^{113}$ In another study half (55\%) of the parents included considered loot boxes to be a form of gambling and should be treated as such in terms of age classifications. ${ }^{114}$

Subsequently, it is not surprising there are also calls for stricter regulation of video games that include gamblingrelated features. ${ }^{115}$ This forms part of a federal Department of Communication review of Australia's classification regulations, with a view to updating regulations drawn up in 1995 to take account of new technology.

\section{Box 10}

Regulating the platforms and advertising agencies?

\section{The ACCC Inquiries into Digital Platforms and Ad Tech}

The Australia Competition and Consumer Commission's Digital Platforms Inquiry, in 2019, led to a set of commitments by the Australian Government, including to hold a 'review of advertising rules and restrictions across all delivery platforms'. This would begin a staged process towards a harmonised regulatory framework covering online and offline content; to ensure that privacy settings empower users and protect data; to take forward a government commitment to increase sanctions for privacy breaches; and introduce a binding online privacy code. This code would include rules specifically to protect vulnerable consumers, including children. (See, as an example, the UK's Age Appropriate Design Code, section 5.) These changes are yet to come into effect. However, were they to be taken forward, they could lead to a reduction in children's exposure to digital marketing of harmful products.

A new ACCC Inquiry into ‘Ad Tech' launched in March $2020^{116}$ and is due to report in August 2021. It is looking at how the automated, targeted system of paid advertising works (see Box 6). 'Ad tech' services are systems that assist with automated ads - such as connecting buyers and sellers, and processing user data/analytics to target marketing and measure the performance of ads. This system is important, as it could be designed in a way that would better enable marketing for certain types of products to be identified, and then restricted for delivery to child users. Making the system more transparent could be a route to prevent children from seeing harmful ads, ${ }^{117}$ but this is not the specific focus of the inquiry. 


\section{Responses from around the world}

Online privacy and the digital marketing of harmful products to children are of international concern and efforts are under way in many countries to tackle them.

\section{Harmful marketing and the World Health Organization}

Digital marketing to children has been a clear concern of the WHO since 2010, when it published a Set of Recommendations on the Marketing of Food and Nonalcoholic Beverages to Children. ${ }^{118}$ These were reiterated in the 2016 report of the WHO Commission on Ending Childhood Obesity, ${ }^{119}$ which called on member states to implement these Recommendations and to work together to tackle cross-border marketing (a particular challenge for digital marketing).

A Regional Action Framework on Protecting Children from the Harmful Impact of Food Marketing in the Western Pacific (the WHO area that covers Australia) notes that the region in general is lagging behind, calling for governments to 'seek input from external experts as needed and as technology develops; for example, monitor the situation of digital marketing and consult with digital law experts, ${ }^{120}$

Action on alcohol is also a current focus of the WHO, with an Action Plan for the period 2022 to 2030 currently under development to speed the implementation of the Global Strategy to Reduce the Harmful Use of Alcohol. Consultation will take place with governments, UN agencies and nonstate actors from late 2020 to mid-2021, with the aim of approval of the Action Plan at the World Health Assembly in 2022. As part of this process, a technical report on the harmful use of alcohol related to cross-border alcohol marketing, advertising and promotional activities is also being developed (for publication in late 2021), specifically including how this affects children and young people. ${ }^{121}$

\section{Alcohol: Finland - restricting advertising on social media}

In 2015, Finland became the first country to restrict alcohol advertising on social media. An amendment to the Alcohol Act prohibits advertisers from putting any content that is 'intended to be shared by consumers' on a social media platform, whether the content is produced by consumers or by the brand itself. ${ }^{122}$

A set of guidelines for alcohol advertisers on interpreting the new amendment was produced by the National Supervisory Authority for Welfare and Health (Valvira), which includes: ${ }^{123}$

- user-generated content may not be distributed through the alcohol company's own website or social media;

- where possible, the advertiser should disable the sharing function on its own social media posts (but this is not always an option - for example, all content on Facebook is shareable); and

- although sponsored advertisements in social media are permitted, the advertiser should ensure that they are targeted at people of legal drinking age - although in practice all the brands' Instagram posts and half of Facebook sites for the brands remain unrestricted to under-18s. ${ }^{124}$

Valvira has no resources for monitoring, but evidence suggests there has been some impact on brands' own social media content. ${ }^{125}$ This could be reflective of more strategic use of the platforms - so it is unclear how much children's actual exposure to alcohol advertising has decreased, if at all. However, the legislation does demonstrate that action is possible. 


\section{Alcohol: France - the Loi Évin}

The French Loi Évin, which covers both alcohol and tobacco marketing, takes a different approach. The law in Finland (and many other countries) bans particular elements of advertising, such as use of a competition or advergame, or portraying an underage drinker. In contrast, the Loi Évin sets out a 'positive' list of what can be advertised: what can, rather than what cannot, be portrayed. This is limited to product information, such as the origin of the product, its ingredients and how it is made. ${ }^{126}$

\section{Unhealthy food: Chile - restrictions on online marketing}

In Chile, the Law of Nutritional Composition of Food and its Advertising has been in effect since June 2016. One of its main goals is to restrict marketing of unhealthy food to children aged under 14 across media platforms including television, radio and online - and it has been shown to have had an effect on the marketing viewed on television. ${ }^{127}$ The restrictions apply to unhealthy food, which is defined as being 'high in' energy, saturated fat, salt or sugar, and to digital content where a website has an audience greater than $20 \%$ of children. ${ }^{128}$

\section{Box 11}

\section{COVID-19 the catalyst for action on unhealthy food marketing in the UK}

The United Kingdom has made a recent commitment to ban marketing for foods high in sugar, fat and salt on television before $9 \mathrm{pm}$ to protect children from the marketing of these harmful products. ${ }^{130}$ As part of the UK's Better Health Strategy, the government has outlined its intention to introduce a total restriction on unhealthy food marketing online by 2022 following a consultation process.

\section{"Our experience shows that there are ways to target children with inappropriate advertising methods - i.e. using games and competitions or peer-to-peer sharing of advertising. We are at an important crossroads: these restrictions could set the scene for further regulation, both in Finland and in other countries"}


Gambling: Italy -

\section{the ‘Dignity Decree’ banning gambling advertising}

In 2006, Italy became the first EU member to comprehensively legalise online gambling - but, 13 years later in July 2019, it also became the first country in Europe to implement a complete ban on marketing of gambling products or services, including betting and gaming sponsorship. This applies to product placement, the distribution of branded items (including offering branded products as prizes), advertisements and - importantly influencer marketing. The only exceptions are 'informative communications' such as sporting odds and minimum bet sizes.

\section{“Italy's ban on gambling sponsorship in sport will help to limit youth exposure to gambling advertising, its normalisation and the 'gamblification' of sport"}

- Professor Nerilee Hing, Central Queensland University ${ }^{131}$

The Italian advertising and communications regulator, AgCom, can investigate operators and media companies that are alleged to be in breach of the regulation, and they can be fined up to $20 \%$ of the value of the advertising contract and at least $€ 50,000$. The impact of the ban is not yet clear.

\section{Privacy: UK - an Age Appropriate Design Code}

In January 2020, the UK's Information Commissioner published an Age Appropriate Design Code ${ }^{132}$ to protect children's online privacy - the first such legislation anywhere in the world. The Code sets out 15 standards applicable to online services, which aim to ensure that children have the best possible access to online services but that their data collection and use is minimised by default.

The standards cover, among other things:

- the need to take into account the 'best interests of the child' - this is explicitly based on the UN Convention on the Rights of the Child

- default privacy settings

- 'nudge' techniques
- appropriate parental controls

- transparency of paid-for activity (e.g. product placement)

- the sharing and resale of data

- the right to erasure, rectification and restriction.

The Code was approved by Parliament and came into force at the start of September 2020. There is now a transitional period of a year, to enable relevant organisations to prepare for implementation. ${ }^{133}$

\section{Box 12}

\section{Involving children and young people}

To protect children from harmful industry marketing, the voices and perspectives of children and young people must be considered when designing policy solutions. This is even more critical when adults are not able to see how children are exposed to harmful marketing in the digital space.

Children can be allies, thought-leaders and influencers in addressing digital marketing, as tobacco-control advocates have long appreciated (for example, the long-running and successful Truth campaign in the United States ${ }^{134}$ ). Young people can take an active part in researching and understanding exposure to harmful industry marketing, providing insights to inform policies to address the concerns that are of most relevance to their age group.

- VicHealth's TopSpin initiative was a state-wide competition in which young people developed creative content that exposed and drew attention to the tactics of the alcohol industry. ${ }^{135}$

- The EU-funded COCREATE initiative brings together 14 international research and advocacy organisations to work with young people to create, inform and promote policies for obesity prevention. ${ }^{136}$ 


\section{Conclusion: time to act}

The digital environment - including the way in which unhealthy food, alcohol and gambling are marketed to children - is a dynamic and rapidly evolving space. Today's industry-led codes (section 4) are proving even less capable of protecting children online than through traditional media. An integrated, system-wide approach is required to ensure that children are able to participate in the benefits of being online, but are protected from the pervasive and targeted marketing of alcohol, unhealthy food and gambling products. To achieve a safe space for children, the full range of ways in which harmful industries can market their products in the digital space should be addressed, with the rights of the child at its heart.

The COVID-19 crisis has sharpened the focus on our online lives, with a perfect storm of increasing screen time and exposure, coupled with increasingly targeted ads. Harmful industries have pivoted their actions in response, ${ }^{137}$ focusing even more on the digital space. There has been a shift away from branded websites and marketing towards consumergenerated content with influencers, and content-sharing between peers and social networks, which are much less available to scrutiny. This is of significant international concern (as section 5 shows) - but Australia is lagging behind in its system of regulation.

There is an opportunity to be part of the worldwide movement to 'build back better' following the pandemic. We can use the spotlight that has been shone on children's digital participation to improve regulation to ensure that society's recovery from COVID-19 prioritises the health and wellbeing of children.
Strong, evidence-based policies and government regulation are required to protect children from digital marketing by harmful industries. This should be backed up by improved monitoring to provide a better picture of children's actual exposure to digital marketing of harmful products. ${ }^{138}$

If change is to be achieved, there must be action across three sectors:

- the platforms (e.g. Google, Facebook, Instagram, YouTube, TikTok, Twitch, Snapchat), to ensure that their processes are transparent and protect children's privacy and data online

- the harmful industries, to ensure that they do not advertise harmful products to children, including through influencers

- the advertising agencies, to ensure that they have processes in place to prevent delivery of inappropriate marketing to children

Australia is falling behind in its regulation both of privacy issues and of digital marketing of harmful products. It is time for government to protect the health and wellbeing of children over the profits of harmful industries. 


\section{References}

These URLS were correct as of 31 August 2020

1 NHMRC 2009, Australian Guidelines to Reduce Health Risks from Drinking Alcohol (currently being reviewed), Canberra: National Health and Medical Research Council. https://www.nhmrc.gov.au/about-us/publications/australian-guidelines-reduce-health-risks-drinkingalcohol

2 NHMRC 2009, Australian Guidelines to Reduce Health Risks from Drinking Alcohol (currently being reviewed), Canberra: National Health and Medical Research Council. https://www.nhmrc.gov.au/about-us/publications/australian-guidelines-reduce-health-risks-drinkingalcohol

3 Lycett, K, Juonala M, Magnussen, CG, et al. 2020, 'Body mass index from early to late childhood and cardiometabolic measurements at 11 to 12 years', Pediatrics, vol. 146, no. 2, e20193666. https://pediatrics.aappublications.org/content/pediatrics/early/2020/07/02/ peds.2019-3666.full.pdf

4 AlHW 2019, Australian Burden of Disease Study: Impact and Causes of Illness and Death in Australia 2015, Australian Burden of Disease Study series no. 18, cat. no. BOD 21, Canberra: AlHW. https://www.aihw.gov.au/getmedia/c076f42f-61ea-4348-9c0a-d996353e838f/aihwbod-22.pdf.aspx?inline=true

5 VRGF 2015. Using a Public Health Approach in the Prevention of Gambling-related Harm, Melbourne: Victorian Responsible Gambling Foundation. https://responsiblegambling.vic.gov.au/documents/21/using-a-public-health-approach-in-the-prevention-of-gamblingrelated-harm.pdf

6 Royal Children's Hospital Melbourne 2020, RCH National Child Health Poll - COVID-19 Pandemic: Effects on the Lives of Australian Children and Families (poll 18, July 2020). https://www.rchpoll.org.au/wp-content/uploads/2020/07/nchp-poll18-report-covid.pdf

7 Sydney Morning Herald 2020, 'Gambling spending up 50 per cent in the time of COVID' (11 June). https://www.smh.com.au/politics/ federal/gambling-spending-up-50-per-cent-in-the-time-of-covid-20200611-p551lf.html

8 Biddle, N, Edwards, B, Gray, Mand Sollis, K 2020. Alcohol Consumption during the COVID-19 Period: May 2020, ANU Centre for Social Research and Methods. https://csrm.cass.anu.edu.au/sites/default/files/docs/2020/6/Alcohol_consumption_during_the_COVID-19_period.pdf

9 Alcohol and Drug Foundation 2020. Kantar Poll Data (July 22-23, 2020). https://www.littlehabit.com.au/about/research/

10 AlHW 2020. National Drug Strategy Household Survey 2019. Drug Statistics series no. 32, PHE 270, Canberra: Australian Institute of Health and Welfare. https://www.aihw.gov.au/getmedia/3564474e-f7ad-461c-b918-7f8de03d1294/aihw-phe-270-NDSHS-2019.pdf. aspx?inline=true

11 Guerin N and White V 2020, ASSAD 2017 Statistics \& Trends: Australian Secondary Students' Use of Tobacco, Alcohol, Over-the-counter Drugs, and Illicit Substances, second edition, Cancer Council Victoria. https://www.health.gov.au/sites/default/files/documents/2020/07/ secondary-school-students-use-of-tobacco-alcohol-and-other-drugs-in-2017.pdf

12 Manning M, Smith C \& Mazerolle P 2013. The societal costs of alcohol misuse in Australia. Trends \& issues in crime and criminal justice No. 454. Canberra: Australian Institute of Criminology. Viewed 4 April 2018

13 ABS 2019a. Microdata: National Health Survey, 2017-18, TableBuilder, ABS cat. no. 4364.0.55.001. Canberra: Australian Bureau of Statistics. Findings based on TableBuilder data, as cited in AlHW 2020, Australia's Children, Canberra: Australian Institute of Health and Welfare, Canberra. https://www.aihw.gov.au/reports/children-youth/australias-children/contents/health/breastfeeding-nutrition

14 AlHW 2018, Nutrition across the Life Stages, Canberra: Australian Institute of Health and Welfare, Table S16: Consumption of discretionary food, by age and sex, 2011-12(a)(b). https://www.aihw.gov.au/reports/food-nutrition/nutrition-across-the-life-stages/data

15 ABS 2019a. Microdata: National Health Survey, 2017-18, TableBuilder, ABS cat. no. 4364.0.55.001. Canberra: Australian Bureau of Statistics. Findings based on TableBuilder data, as cited in AlHW 2020, Australia's Children, Canberra: Australian Institute of Health and Welfare, Canberra. https://www.aihw.gov.au/reports/children-youth/australias-children/contents/health/breastfeeding-nutrition

16 ABS 2018, National Health Survey: First Results, 2017-18, cat. no. 4364.0.55.001, Canberra: Australian Bureau of Statistics. https:// www.abs.gov.au/ausstats/abs@.nsf/Lookup/by\%20Subject/4364.0.55.001 2017-18 Main\%20Features Children's\%20risk\%20 factors 120

17 ABS 2019b. Microdata: National Health Survey, 2017-18. ABS cat. no. 4324.0.55.001, Canberra: Australian Bureau of Statistics, customised data report, as cited in AIHW 2020b, Australia's Children: Overweight and Obesity, cat. no. CWS 69, Canberra: Australian Institute of Health and Welfare. https://www.aihw.gov.au/reports/children-youth/australias-children/contents/health/overweight-and-obesity

18 ABS 2019b. Microdata: National Health Survey, 2017-18. ABS cat. no. 4324.0.55.001, Canberra: Australian Bureau of Statistics, customised data report, as cited in AIHW 2020b, Australia's Children: Overweight and Obesity, cat. no. CWS 69, Canberra: Australian Institute of Health and Welfare. https://www.aihw.gov.au/reports/children-youth/australias-children/contents/health/overweight-and-obesity

19 ABS 2019b. Microdata: National Health Survey, 2017-18. ABS cat. no. 4324.0.55.001, Canberra: Australian Bureau of Statistics, customised data report, as cited in AlHW 2020b, Australia's Children: Overweight and Obesity, cat. no. CWS 69, Canberra: Australian Institute of Health and Welfare. https://www.aihw.gov.au/reports/children-youth/australias-children/contents/health/overweight-and-obesity

20 Crosland, P, Ananthapavan, J, Davison, J, Lambert, M and Carter, R 2019, 'The economic cost of preventable disease in Australia: a systematic review of estimates and methods', Australian and New Zealand Journal of Public Health, vol. 43, no. 5, pp. 484-95. https://doi. org/10.1111/1753-6405.12925

21 Crosland, P, Ananthapavan, J, Davison, J, Lambert, M and Carter, R 2019, 'The economic cost of preventable disease in Australia: a systematic review of estimates and methods', Australian and New Zealand Journal of Public Health, vol. 43, no. 5, pp. 484-95. https://doi. org/10.1111/1753-6405.12925 
22 Black, N, Hughes, R and Jones, AM 2018, 'The health care costs of childhood obesity in Australia: an instrumental variables approach’ Economics and Human Biology, vol. 31, pp. 1-13. https://doi.org/10.1016/j.ehb.2018.07.003

23 Freund, M, Noble, N, Hill, D, White, V, Evans, T, Oldmeadow, C and Sanson-Fisher, R 2019, The Prevalence and Correlates of Gambling in Secondary School Students in Victoria, Australia, 2017, Melbourne: Victorian Responsible Gambling Foundation. https:// responsiblegambling.vic.gov.au/resources/publications/the-prevalence-and-correlates-of-gambling-in-secondary-school-studentsin-victoria-australia-2017-680/

24 Freund, M, Noble, N, Hill, D, White, V, Evans, T, Oldmeadow, C and Sanson-Fisher, R 2019, The Prevalence and Correlates of Gambling in Secondary School Students in Victoria, Australia, 2017, Melbourne: Victorian Responsible Gambling Foundation. https:// responsiblegambling.vic.gov.au/resources/publications/the-prevalence-and-correlates-of-gambling-in-secondary-school-studentsin-victoria-australia-2017-680/

25 VRGF 2017, Gen Bet: Has Gambling Gatecrashed our Teens? Melbourne: Victorian Responsible Gambling Foundation. https:// responsiblegambling.vic.gov.au/resources/publications/gen-bet-has-gambling-gatecrashed-our-teens-16/

26 Browne, M, Greer, N, Armstrong, T, Doran, C, Kinchin, I, Langham, E and Rockloff, M, 2017, The Social Cost of Gambling to Victoria, Melbourne: Victorian Responsible Gambling Foundation. https://responsiblegambling.vic.gov.au/resources/publications/the-social-cost-ofgambling-to-victoria-121/

27 ACMA 2019a, Kids and Mobiles: How Australian Children are using Mobile Phones, Australian Communications and Media Authority. https:// www.acma.gov.au/publications/2019-11/report/kids-and-mobiles-how-australian-children-are-using-mobile-phones

28 Roy Morgan 2016, ' 9 in 10 Aussie teens now have a mobile (and most are already on to their second or subsequent hand set)' (finding no. 6929, press release, 22 August). http://www.roymorgan.com/findings/6929-australian-teenagers-and-their-mobile-phonesjune-2016-201608220922

29 ABS 2018, Household Use of Information Technology, Australia, 2016-17, Canberra: Australian Bureau of Statistics. https://www.abs.gov. au/ausstats/abs@.nsf/mf/8146.0

30 APS 2017, Digital Me Survey, Australian Psychological Society. https://psychweek.org.au/2017/digital-me-survey/

31 Office of the eSafety Commissioner 2018, 'Young people and social media usage', https://www.esafety.gov.au/about-us/research/ youth-digital-dangers/social-media-usage, sourced from Office of the eSafety Commissioner 2018, State of Play - Youth, Kids and Digital Dangers. https://www.esafety.gov.au/sites/default/files/2019-10/State\%20of\%20Play\%20-\%20Youth\%20kids\%20and\%20digital\%20 dangers.pdf

32 New York Times 2020, 'A third of TikTok's U.S. users may be 14 or under, raising safety questions' (updated 26 August). https://www. nytimes.com/2020/08/14/technology/tiktok-underage-users-ftc.html

33 Brand, JE, Jervis, J, Huggins, PM, Wilson, TW 2019, Digital Australia 2020: The Power of Games, Eveleight: Interactive Games and Entertainment Association. https://igea.net/2019/07/digital-australia-2020-da20/

34 Royal Children's Hospital Melbourne 2020, RCH National Child Health Poll - COVID-19 Pandemic: Effects on the Lives of Australian Children and Families (poll 18, July 2020) https://www.rchpoll.org.au/wp-content/uploads/2020/07/nchp-poll18-report-covid.pdf

35 Tatlow-Golden, M, Boyland, E, Jewell, J, Zalnieriute, M, Handsley, E and Breda, J, 2016, Tackling Food Marketing to Children in a Digital World: Trans-disciplinary Perspectives, Copenhagen: WHO Regional Office for Europe. http://www.euro.who.int/en/health-topics/diseaseprevention/nutrition/publications/2016/tackling-food-marketing-to-children-in-a-digital-world-trans-disciplinary-perspectives.childrens-rights,-evidence-of-impact,-methodological-challenges,-regulatory-options-and-policy-implications-for-the-whoeuropean-region-2016

36 OHCHR 1990, Convention on the Rights of the Child, United Nations Office of the Commissioner on Human Rights. https://www.ohchr.org/ en/professionalinterest/pages/crc.aspx

37 Tatlow-Golden, M, Boyland, E, Jewell, J, Zalnieriute, M, Handsley, E and Breda, J, 2016, Tackling Food Marketing to Children in a Digital World: Trans-disciplinary Perspectives, Copenhagen: WHO Regional Office for Europe. http://www.euro.who.int/en/health-topics/diseaseprevention/nutrition/publications/2016/tackling-food-marketing-to-children-in-a-digital-world-trans-disciplinary-perspectives.childrens-rights,-evidence-of-impact,-methodological-challenges,-regulatory-options-and-policy-implications-for-the-whoeuropean-region-2016

38 UNICEF / UN Global Compact / Save the Children 2012, Children's Rights and Business Principles. https://www.unicef.org/csr/47.htm

39 ICO 2020a. 'ICO publishes Code of Practice to protect children's privacy online' (press release, 21 January 2020$)$, London: Information Commissioner's Office (UK). https://ico.org.uk/about-the-ico/news-and-events/news-and-blogs/2020/01/ico-publishes-code-ofpractice-to-protect-children-s-privacy-online/

40 Hickey K, Mandelbaum J, Bloom Kand Martin, J 2018, Overbranded, Underprotected: How Industry Self-regulation is Failing to Protect Children from Unhealthy Food Marketing, Obesity Policy Coalition, Melbourne. https://www.opc.org.au/downloads/overbranded/overbrandedunderprotected.pdf

41 Which-50 2020. 'Cover story: Australia is ‘falling behind’ on protecting children's online privacy' (16 March). https://which-50.com/ cover-story-australia-is-falling-behind-on-protecting-childrens-online-privacy/

42 Superawesome. 2017. Blog: How much data do adtech companies collect on kids before they turn 13. Available from: https://blog. superawesome.tv/2017/12/13/how-much-data-do-adtech-companies-collect-on-kids-before-they-turn-13/ 
43 Livingstone, S, Stoilova, M and Nandagiri, R 2018, Children's Data and Privacy Online: Growing up in a Digital Age - An Evidence Review, London: LSE Media and Communications. http://www.lse.ac.uk/media-and-communications/assets/documents/research/projects/ childrens-privacy-online/Evidence-review-final.pdf

44 FARE 2019, FARE Submission to Australian Government ACCC Digital Platforms Inquiry, Canberra: Foundation for Alcohol Research and Education. http://fare.org.au/wp-content/uploads/ACCC-Inquiry-into-Digital-Platforms_FARE-Submission_FINAL.pdf

45 Which-50 2020, 'Cover story: Australia is 'falling behind' on protecting children's online privacy' (16 March). https://which-50.com/ cover-story-australia-is-falling-behind-on-protecting-childrens-online-privacy/

46 Critchlow N, Angus, K, Stead, M, Newberry Le Vay, J, Whiteside, E, Clark, M, Hudson, B and Vohra, J, 2019, Digital Feast: Navigating a Digital Marketing Mix, and the Impact on Children and Young People's Dietary Attitudes and Behaviours, London: Cancer Research UK. https://www. cancerresearchuk.org/sites/default/files/cancer-stats/digital_feast_june_2019__full_report/digital_feast_june_2019__full_report. pdf

47 WHO 2016, Report of the Commission to End Childhood Obesity, Geneva:WHO. https://www.who.int/end-childhood-obesity/publications/ echo-plan-executive-summary/en/

48 WHO Europe 2019b, Evaluating Implementation of the WHO Set of Recommendations on the Marketing of Foods and Non-alcoholic Beverages to Children, Copenhagen: WHO Regional Office for Europe. http://www.euro.who.int/en/health-topics/disease-prevention/nutrition/ publications/2018/evaluating-implementation-of-the-who-set-of-recommendations-on-the-marketing-of-foods-and-non-alcoholicbeverages-to-children.-progress,-challenges-and-guidance-for-next-steps-in-the-who-european-region

49 WHO Europe 2019b, Evaluating Implementation of the WHO Set of Recommendations on the Marketing of Foods and Non-alcoholic Beverages to Children, Copenhagen: WHO Regional Office for Europe. http://www.euro.who.int/en/health-topics/disease-prevention/nutrition/ publications/2018/evaluating-implementation-of-the-who-set-of-recommendations-on-the-marketing-of-foods-and-non-alcoholicbeverages-to-children.-progress,-challenges-and-guidance-for-next-steps-in-the-who-european-region

50 Kelly, S and Gerrish, R 2019, Sponsorship Activation in Esports: A Content Analysis of Alcohol, Energy Drinks, Junk Food, and Gambling Category Sponsorship. Foundation for Alcohol Research and Education: Canberra. http://www.endalcoholadvertisinginsport.org.au/wp-content/ uploads/2019/09/Sponsorship-Activation-in-Esports_web.pdf

51 Hendriks, H, Wilmsen, D, van Dalen, W and Gebhardt, WA 2020, 'Picture me drinking: alcohol-related posts by Instagram influencers popular among adolescents and young adults', Frontiers in Psychology, vol. 10, p. 2991. https://www.frontiersin.org/article/10.3389/ fpsyg.2019.02991

52 The ABAC Scheme 2019, ABAC Adjudication Panel Determination No. 30/19. http://www.abac.org.au/wp-content/uploads/2019/06/3019-Determination-Jimmy-Brings-3-June-2019.pdf

53 Baldwin, HJ, Freeman, B and Kelly, B 2018, 'Like and share: associations between social media engagement and dietary choices in children' Public Health Nutr, vol. 21, no. 17, pp. 3210-15. https://pubmed.ncbi.nlm.nih.gov/30086811/

54 Smith R, Kelly B, Yeatman H, Moore C, Baur L, King L, and Bauman, A 2019, 'Advertising placement in digital game design influences children's choices of advertised snacks: a randomized trial', Journal of the Academy of Nutrition and Dietetics, vol. 120, no. 3, pp. 404-13. https://pubmed.ncbi.nlm.nih.gov/31892500/

55 Abarbanel, B, Gainsbury, SM, King, D, Hing, N, Delfabbro, PH 2016, Gambling games on social platforms: how do advertisements for social casino games target young adults?', Policy \& Internet, vol. 9, no. 2, pp. 184-209. https://onlinelibrary.wiley.com/doi/abs/10.1002/ poi3.135

56 Abarbanel, B, Gainsbury, SM, King, D, Hing, N, Delfabbro, PH 2016, Gambling games on social platforms: how do advertisements for social casino games target young adults?', Policy \& Internet, vol. 9, no. 2, pp. 184-209. https://onlinelibrary.wiley.com/doi/abs/10.1002/ poi3.135

57 Zendle, D 2020, 'The rise of social casino games: changes in the size and composition of the Android social casino market from 20122020, availability to children, and predictions for future growth', PsyArXiv preprints (March). https://psyarxiv.com/safhv

58 Murphy, G, Corcoran, C, Tatlow-Golden, M, Boyland, E and Rooney, B 2020, 'Adolescents' responses to unhealthy-, healthy- and non-food advertising in social media', Int. J. Environ. Res. Public Health, vol 17, no. 7, p. 2181. https://doi.org/10.3390/ijerph17072181

59 VRGF 2017. Gen Bet: Has Gambling Gatecrashed our Teens? Melbourne: Victorian Responsbile Gambling Foundation. https:// responsiblegambling.vic.gov.au/resources/publications/gen-bet-has-gambling-gatecrashed-our-teens-16/

60 Murphy, G, Corcoran, C, Tatlow-Golden, M, Boyland, E and Rooney, B 2020, 'Adolescents' responses to unhealthy-, healthy- and non-food advertising in social media', Int. J. Environ. Res. Public Health, vol 17, no. 7, p. 2181. https://doi.org/10.3390/ijerph17072181

61 Noel, JK, Lazzarini, Z, Robaina, K and Vendrame, A 2017, 'Alcohol Industry self-regulation: who is it really protecting?', Addiction, vol. 112(S1), pp. 57-63 https://doi.org/10.1111/add.13433 and Hickey K, Mandelbaum J, Bloom K, Martin J, 2018. Overbranded, Underprotected: How industry Self-regulation is Failing to Protect Children from Unhealthy Food Marketing, Obesity Policy Coalition, Melbourne. https://www.opc.org.au/downloads/overbranded/overbranded-underprotected.pdf

62 Sargent, JD and Babor, TF 2020, 'The relationship between exposure to alcohol marketing and underage drinking is causal' Journal of Studies on Alcohol and Drugs, Supplement (s19), pp. 113-24. https://doi.org/10.15288/jsads.2020.s19.113

63 Jernigan, D, Noel, H, Landon, J, Thornton, N and Lobstein, T 2017, 'Alcohol marketing and youth alcohol consumption: a systematic review of longitudinal studies published since 2008', Addiction, vol. 112(S1), pp. 7-20. https://doi.org/10.1111/add.13591

64 Critchlow, N, MacKintosh, AM, Hooper, L, Thomas, C and Vohra, J 2019, 'Participation with alcohol marketing and user-created promotion on social media, and the association with higher-risk alcohol consumption and brand identification among adolescents in the UK', Addiction Research \& Theory, vol. 27, no. 6, pp. 515-26. https://doi.org/10.1080/16066359.2019.1567715

65 Baldwin, HJ, Freeman, B and Kelly, B 2018, 'Like and share: associations between social media engagement and dietary choices in children', Public Health Nutr, vol. 21, no. 17, pp. 3210-15. https://pubmed.ncbi.nlm.nih.gov/30086811/

66 Boyland, E, Thivel, D, Mazur, Ring-Dimitriou, S, Frelut, M-L and Weghuber, D 2020, 'Digital food marketing to young people: a substantial public health challenge', Ann Nutr Metab, vol. 76, pp. 6-9. https://doi.org/10.1159/000506413 
67 Murphy, G, Corcoran, C, Tatlow-Golden, M, Boyland, E and Rooney, B 2020, 'Adolescents' responses to unhealthy-, healthy- and non-food advertising in social media', Int. J. Environ. Res. Public Health, vol 17, no. 7, p. 2181. https://doi.org/10.3390/ijerph17072181

68 Thomas, SL, Bestman, A, Pitt, H, Cassidy, R, McCarthy, S, Nyemcsok, C, Cowlishaw, S and Daube, M 2018, 'Young people's awareness of the timing and placement of gambling advertising on traditional and social media platforms: a study of 11-16-year-olds in Australia', Harm Reduction Journal, vol. 15, no. 51, pp. 1-13. http://dro.deakin.edu.au/eserv/DU:30114740/thomas-youngpeoples-2018.pdf

69 Thomas, SL, Pitt, H, Bestman, A, Randle, M, Daube, M and Pettigrew, S 2016, Child and Parent Recall of Gambling Sponsorship in Australian Sport, Melbourne: Victorian Responsible Gambling Foundation. https://responsiblegambling.vic.gov.au/resources/publications/childand-parent-recall-of-gambling-sponsorship-in-australian-sport-67/

70 Freund, M, Noble, N, Hill, D, White, V, Evans, T, Oldmeadow, C and Sanson-Fisher, R 2019, The Prevalence and Correlates of Gambling in Secondary School Students in Victoria, Australia, 2017, Melbourne: Victorian Responsible Gambling Foundation. https:// responsiblegambling.vic.gov.au/resources/publications/the-prevalence-and-correlates-of-gambling-in-secondary-school-studentsin-victoria-australia-2017-680/

71 Freund, M, Noble, N, Hill, D, White, V, Evans, T, Oldmeadow, C and Sanson-Fisher, R 2019, The Prevalence and Correlates of Gambling in Secondary School Students in Victoria, Australia, 2017, Melbourne: Victorian Responsible Gambling Foundation. https:// responsiblegambling.vic.gov.au/resources/publications/the-prevalence-and-correlates-of-gambling-in-secondary-school-studentsin-victoria-australia-2017-680/

72 Critchlow, N, MacKintosh, AM, Hooper, L, Thomas, C and Vohra, J 2019, 'Participation with alcohol marketing and user-created promotion on social media, and the association with higher-risk alcohol consumption and brand identification among adolescents in the UK', Addiction Research \& Theory, vol. 27, no. 6, pp. 515-26. https://doi.org/10.1080/16066359.2019.1567715, p. 516.

73 The Australian 2017, 'Facebook targets insecure young people to sell ads' (1 May). http://www.theaustralian.com.au/business/media/ digital/facebook-targets-insecure-young-people-to-sell-ads/news-story/a89949ad016eee7d7a61c3c30c909fa6

74 FARE 2020, An Alcohol Ad every 35 Seconds, Deakin: Foundation for Alcohol Research and Education. https://fare.org.au/wp-content/ uploads/2020-05-08-CCWA-FARE-An-alcohol-ad-every-35-seconds-A-snapshot-final.pdf

75 OPC 2020, 'Junk food brands capitalising on lockdown: public health groups criticise companies' opportunistic marketing during COVID-19 pandemic' (media release, 10 May). https://www.opc.org.au/media/media-releases/junk-food-brands-capitalising-onlockdown.html

76 Hendriks, H, Wilmsen, D, van Dalen, W and Gebhardt, WA 2020. 'Picture me drinking: alcohol-related posts by Instagram influencers popular among adolescents and young adults', Frontiers in Psychology, vol. 10, p. 2991. https://www.frontiersin.org/article/10.3389/ fpsyg.2019.02991

77 Tatlow-Golden, M, Verdoodt, V, Oates, J, Jewell, J, Breda, JJ and Boyland, E 2017, 'A safe glimpse within the "black box"? Ethical and legal principles when assessing digital marketing of food and drink to children', Journal of the WHO Regional Office for Europe: Public Health Panorama, vol. 3, no. 4, pp.613-32. http://www.euro.who.int/_data/assets/pdf_file/0019/357301/PHP-1127-BlackBox-eng.pdf?ua=1

78 AdNews 2019, 'Zenith: Programmatic is now 55\% of digital advertising spend in Australia' (25 November). https://www.adnews.com.au/ news/zenith-programmatic-is-now-55-of-digital-advertising-spend-in-australia

79 e-Marketer 2019, 'UK programmatic digital display ad spending' (1 November). https://www.emarketer.com/content/ukprogrammatic-digital-display-ad-spending

80 Buchanan, L, Kelly, B, Yeatman, H and Kariippanon, K 2018, 'The effects of digital marketing of unhealthy commodities on young people: a systematic review', Nutrients, vol. 10, no. 2, p. 148. https://doi.org/10.3390/nu10020148

81 Hendriks, H, Wilmsen, D, van Dalen, W and Gebhardt, WA 2020. 'Picture me drinking: alcohol-related posts by Instagram influencers popular among adolescents and young adults', Frontiers in Psychology, vol. 10, p. 2991. https://www.frontiersin.org/article/10.3389/ fpsyg.2019.02991

82 Business Insider 2019, 'Influencer marketing: state of the social media influencer market in 2020'. https://www.businessinsider.com/ influencer-marketing-report?r=US\&IR=T

83 Hendriks, H, Wilmsen, D, van Dalen, W and Gebhardt, WA 2020, 'Picture me drinking: alcohol-related posts by Instagram influencers popular among adolescents and young adults', Frontiers in Psychology vol. 10, p. 2991. https://www.frontiersin.org/article/10.3389/ fpsyg.2019.02991

84 VicHealth 2020, Teens and Junk Food Social Influence Report. [not in public domain]

85 Coates, AE, Hardman, CA, Halford, JGC, Christiansen, P and Boyland, EJ 2019, 'The effect of influencer marketing of food and a "protective" advertising disclosure on children's food intake', Pediatric Obesity, vol. 14, no. 10, p. e12540. https://doi.org/10.1111/ ijpo.12540

86 VicHealth 2020, Teens and Junk Food Social Influence Report. [not in public domain]

87 Twitchtracker.com 2020, 'Twitch statistics and charts'. https://twitchtracker.com/statistics

88 Business of Apps 2020, 'Twitch revenue and usage statistics (2020)' (23 June) https://www.businessofapps.com/data/twitchstatistics/

89 AdNews 2018, 'Amazon's gaming platform Twitch ramps up ad opportunities in Anz' (18 June). https://www.adnews.com.au/news/ amazon-s-gaming-platform-twitch-ramps-up-ad-opportunities-in-anz

90 Streamlabs 2020, ‘Blog: Streamlabs, Stream Hatchet, Q1 2020 live streaming industry report'. https://blog.streamlabs.com/ streamlabs-stream-hatchet-q1-2020-Live-streaming-industry-report-9630bc3e0e1e

91 Pollack, CC, Kim, J, Emond, J, Brand, J, Gilbert-Diamond, D and Masterson, T 2020, 'Prevalence and strategies of energy drink, soda, processed snack, candy and restaurant product marketing on the online streaming platform Twitch' Public Health Nutrition, pp.1-11.https://www.cambridge.org/core/journals/public-health-nutrition/article/prevalence-and-strategies-ofenergy-drink-soda-processed-snack-candy-and-restaurant-product-marketing-on-the-online-streaming-platform-twitch/ F2E07B2E205EFABEE2420E14F7B1F874 
92 King, D 2018. Online Gaming and Gambling in Children and Adolescents - Normalising Gambling in Cyber Places, Melbourne: Victorian Responsible Gambling Foundation https://responsiblegambling.vic.gov.au/resources/publications/online-gaming-and-gamblingin-children-and-adolescents-normalising-gambling-in-cyber-places-479/ and Browne, B 2020, Gambling on Games: How Video Games expose Children to Gambling, Canberra: Australia Institute, Centre for Responsible Technology https://www.tai.org.au/sites/default/ files/P860\%20Risks\%20to\%20kids\%20from\%20vide0\%20games\%20\%5BWeb\%5D.pdf

93 King, D 2018. Online Gaming and Gambling in Children and Adolescents - Normalising Gambling in Cyber Places, Victorian Responsible Gambling Foundation, Melbourne. https://responsiblegambling.vic.gov.au/resources/publications/online-gaming-and-gambling-inchildren-and-adolescents-normalising-gambling-in-cyber-places-479/

94 Outdoor Media Association 2019, A Healthy Media Plan. https://www.oma.org.au/healthy-media-plan

95 Richmond, KJ, Watson, WL, Hughes, C and Kelly, B 2020, 'Children's trips to school dominated by unhealthy food advertising in Sydney, Australia', Public Health Res Prac, vol. 30, no. 1, pp. e3012005 https://www.phrp.com.au/issues/march-2020-volume-30-issue-1/ childrens-trips-to-school-dominated-by-unhealthy-food-advertising-in-sydney-australia/

96 Sainsbury, E, Colagiuri, S and Magnusson, R 2017, 'An audit of food and beverage advertising on the Sydney metropolitan train network: regulation and policy implications' BMC Public Health vol. 17, no. 1, pp. 490 https://bmcpublichealth.biomedcentral.com/ articles/10.1186/s12889-017-4433-2 and Settle, PJ, Cameron, AJ and Thornton, LE 2014, 'Socioeconomic differences in outdoor food advertising at public transit stops across Melbourne suburbs', Australian and New Zealand Journal of Public Health, vol. 38, no. 5, pp. 414-18 https://onlinelibrary.wiley.com/doi/full/10.1111/1753-6405.12257

97 Ad New 2020. 'Analysis: Behind the billboards in Australia's out-of-home market' (25 February). https://www.adnews.com.au/news/ analysis-behind-the-billboards-in-australia-s-out-of-home-market

98 AANA 2014, Code for Advertising and Marketing Communications to Children, Sydney: Australian Association of National Advertisers. https:// aana.com.au/content/uploads/2014/05/AANA-Code-For-Marketing-Advertising-Communications-To-Children.pdf

99 Ad Standards (undated), 'Wagering advertising'. https://adstandards.com.au/issues/wagering-advertising

100 AIMCO 2020, Australian Influencer Marketing Code of Practice (1 July), Sydney: Australia Influencer Marketing Council. https://www. auditedmedia.org.au/site/assets/media/AIMCO-docs/AIMCO_Code_of_Practice_July-1-2020.pdf

101 Reeve, B 2018, 'Regulation of alcohol advertising in Australia: does the ABAC scheme adequately protect young people from marketing of alcoholic beverages?', QUT Law Review, vol. 18, n o. 1, pp. 96-123. https://papers.ssrn.com/sol3/papers.cfm?abstract_id=3299110

102 ANPHA 2014, Alcohol Advertising: The Effectiveness of Current Regulatory Codes in Addressing Community Concern: Final Report, Canberra: Australian National Preventative Health Agency. http://www.fare.org.au/wp-content/uploads/Alcohol-Advertising-Final-Report-30April-2014.pdf

103 Wallbank, P 2018, 'Beer brands' influencer campaigns breached guidelines, watchdog finds' (Mumbrella, 19 0ctober). https:// mumbrella.com.au/beer-brands-influencer-campaigns-breached-alcohol-advertising-guidelines-watchdog-findes-547271

104 FARE 2019, Letter to AANA: Code of Ethics Review (18 0ctober) [not in public domain]

105 Hickey K, Mandelbaum J, Bloom K and Martin, J 2018, Overbranded, Underprotected: How Industry Self-Regulation is Failing to Protect Children from Unhealthy Food Marketing, Melbourne: Obesity Policy Coalition. https://www.opc.org.au/downloads/overbranded/ overbranded-underprotected.pdf

106 See Advertising Standards Community Panel (or Advertising Standards Board) case reports: 0299/19, 0102/17 and 0107/19.

107 Federal Register of Legislation 2001, Interactive Gambling Act (No. 84, 2001; as amended and in force on 13 December 2019). https:// www.legislation.gov.au/Details/C2020C00027

108 ACMA 2019b, 'Standards and codes for TV and radio broadcasters', Australia Communications and Media Authority https://www.acma. gov.au/standards-and-codes-tv-and-radio-broadcasters and Federal Register of Legislation, Broadcasting Services (Online Content Service Provider Rules) 2018 https://www.legislation.gov.au/Details/F2018L01203

109 O'Brien, K \& Iqbal, M 2019, Extent of, and children and young people's exposure to, gambling advertising in sport and non-sport TV, Melbourne: Victorian Responsible Gambling Foundation. https://responsiblegambling.vic.gov.au/resources/publications/extent-of-and-childrenand-young-peoples-exposure-to-gambling-advertising-in-sport-and-non-sport-tv-679/

110 Thomas, SL, Bestman, A, Pitt, H, Cassidy, R, McCarthy, S, Nyemcsok, C, Cowlishaw, S and Daube, M 2018, 'Young people's awareness of the timing and placement of gambling advertising on traditional and social media platforms: a study of 11-16-year-olds in Australia', Harm Reduction Journal, vol. 15, no. 51, pp. 1-13. http://dro.deakin.edu.au/eserv/DU:30114740/thomas-youngpeoples-2018.pdf

111 Federal Register of Legislation 2001, Interactive Gambling Act (No. 84, 2001; as amended and in force on 13 December 2019). https:// www.legislation.gov.au/Details/C2020C00027

112 King, D, 2018. Online Gaming and Gambling in Children and Adolescents - Normalising Gambling in Cyber Places, Melbourne: Victorian Responsible Gambling Foundation. https://responsiblegambling.vic.gov.au/resources/publications/online-gaming-and-gambling-inchildren-and-adolescents-normalising-gambling-in-cyber-places-479/

113 Department of Communications and the Arts 2019, Computer Games Content Research: Final Report. https://www.classification.gov.au/ sites/default/files/2019-10/computer-games-content-research-final-report-january2019.pdf

114 Department of Communication and the Arts 2019, Classification survey report: loot boxes and simulated gambling in games, Canberra. https://www.classification.gov.au/sites/default/files/2019-10/classification-survey-report-loot-boxes-and-simulated-gamblingin-games-novemberanddecember2018.pdf

115 Browne, B, 2020, Gambling on Games: How Video Games expose Children to Gambling, Canberra: Centre for Responsible Technology, Australia Institute. https://www.tai.org.au/sites/default/files/P860\%20Risks\%20to\%20kids\%20from\%20vide0\%20games\%20 \%5BWeb\%5D.pdf

116 ACCC 2020a, 'Ad tech and ad agency services inquiry kicks off' (10 March), Australian Competition and Consumer Commission. https:// www.accc.gov.au/media-release/ad-tech-and-ad-agency-services-inquiry-kicks-off

117 ACCC 2020b, Ad Tech Inquiry Issues Paper (March), Australian Competition and Consumer Commission. https://www.accc.gov.au/system/ files/Ad\%20tech\%20inquiry\%20-\%20issues\%20paper.pdf 
118 WHO 2010, Set of Recommendations on the Marketing of Foods and Non-alcoholic Beverages to Children, Geneva: WHO. https://www.who.int/ dietphysicalactivity/publications/recsmarketing/en/

119 WHO 2016, Report of the Commission to End Childhood Obesity, Geneva: WHO. https://www.who.int/end-childhood-obesity/ publications/echo-plan-executive-summary/en/

120 WPRO 2020, Regional Action Framework on Protecting Children from the Harmful Impact of Food Marketing in the Western Pacific, Manila: WHO Regional Office for the Western Pacific. https://iris.wpro.who.int/handle/10665.1/14501

121 WHO 2020, 'WHO to accelerate action to reduce the harmful use of alcohol' (departmental news, 28 March). https://www.who.int/ news-room/detail/28-03-2020-who-to-accelerate-action-to-reduce-the-harmful-use-of-alcohol

122 Kauppila, E, Lindeman, M, Svensson, J, Hellman, M, and Katainen, A, 2019. Alcohol Marketing on Social Media Sites in Finland and Sweden: A Comparative Audit Study of Brands' Presence and Content, and the Impact of a Legislative Change, Helsinki, Finland: Faculty of Social Sciences, University of Helsinki. https://helda.helsinki.fi/bitstream/handle/10138/303690/Alcohol_marketing_on_social_media_sites_in_ Finland_and_Sweden_2019.pdf?sequence=1

123 Kauppila, E, Lindeman, M, Svensson, J, Hellman, M, and Katainen, A, 2019. Alcohol Marketing on Social Media Sites in Finland and Sweden: A Comparative Audit Study of Brands' Presence and Content, and the Impact of a Legislative Change, Helsinki, Finland: Faculty of Social Sciences, University of Helsinki. https://helda.helsinki.fi/bitstream/handle/10138/303690/Alcohol_marketing_on_social_media_sites_in_ Finland_and_Sweden_2019.pdf?sequence=1

124 Katainen, A, Kauppila, E, Svensson, J, Lindeman, M and Hellman, M 2020, 'Regulating alcohol marketing on social media: outcomes and limitations of marketing restrictions in Finland's Alcohol Act'. https://tuhat.helsinki.fi/ws/portalfiles/portal/129785500/Katainen. et_al_Regulating_Alcohol_Marketing_on_Social_Media.pdf

125 Katainen, A, Kauppila, E, Svensson, J, Lindeman, M and Hellman, M 2020, 'Regulating alcohol marketing on social media: outcomes and limitations of marketing restrictions in Finland's Alcohol Act'. https://tuhat.helsinki.fi/ws/portalfiles/portal/129785500/Katainen. et_al_Regulating_Alcohol_Marketing_on_Social_Media.pdf

126 For a description of the law, and a 2020 case, see Movendi International 2020, 'France: alcohol advertising ban wins case in High Court' (19 June). https://movendi.ngo/news/2020/06/19/france-alcohol-advertising-ban-wins-case-in-high-court/

127 Dillman Carpentier, FR, Correa, T, Reyes, M, and Smith Taillie, L 2020, 'Evaluating the impact of Chile's marketing regulation of unhealthy foods and beverages: preschool and adolescent children's changes in exposure to food advertising on television', Public Health Nutr, vol. 23, no. 4, pp. 747-55. https://www.ncbi.nlm.nih.gov/pmc/articles/PMC7060093/

128 See e.g. NOURISHING 2020, 'Policy actions: Chile - the Law on Nutritional Composition of Food and its Advertising (Ley 20.606)', London: World Cancer Research Fund. https://policydatabase.wcrf.org/level_one?page=nourishing-level-one\#step2=3\#step3=329

129 Cited in WHO Europe 2019a. Monitoring and Restricting Digital Marketing of Unhealthy Products to Children and Adolescents, Copenhagen: World Health Organization Regional Office for Europe. http://www.euro.who.int/en/health-topics/disease-prevention/nutrition/ publications/2019/monitoring-and-restricting-digital-marketing-of-unhealthy-products-to-children-and-adolescents-2019

130 DHSC 2020, Policy Paper: Tackling Obesity: Empowering Adults and Children to Live Healthier Lives, London: Department of Health and Social Care (UK). https://www.gov.uk/government/publications/tackling-obesity-government-strategy/tackling-obesity-empoweringadults-and-children-to-live-healthier-lives

131 Quoted in International Association of Gaming Regulators 2019, ‘Gambling ads in focus in Italy and Spain' (15 February). https://www. iagr.org/industry-news/gambling-ads-focus-italy-and-spain

132 ICO 2020b. Age Appropriate Design: A Code of Practice for Online Services, London: Information Commissioner’s Office (UK). https://ico. org.uk/for-organisations/guide-to-data-protection/key-data-protection-themes/age-appropriate-design-a-code-of-practice-foronline-services/

133 DCMS 2020, Explanatory Memorandum to the Age Appropriate Design Code 2020, London: Department for Culture, Media and Sport (UK). https://www.gov.uk/government/publications/explanatory-memorandum-to-the-age-appropriate-design-code-2020-2020/ explanatory-memorandum-to-the-age-appropriate-design-code-2020-2020

134 Truth (undated). Accessed 20/07/2020: https://www.thetruth.com/

135 VicHealth 2019, 'Top Spin: young people and alcohol industry tactics social media graphics competition'. Accessed 20/07/2020: https:// www.vichealth.vic.gov.au/programs-and-projects/top-spin

136 COCREATE (undated). Accessed 20/07/2020 https://www.fhi.no/en/studies/co-create/

137 See, for example, ATNI 2020, Nutrition Responses from Food and Beverage Companies to the Covid-19 Pandemic: Report 1 - Framework, Utrecht: Access to Nutrition Initiative. https://accesstonutrition.org/app/uploads/2020/07/First-quarterly-COVID-report-Finalversion.pdf

138 Thomas, SL, David, J, Randle, M, Daube, M and Senior, K 2016, 'Gambling advocacy: lessons from tobacco, alcohol and junk food', Australian and New Zealand Journal of Public Health, vol. 40, no. 3, pp. 211-17. https://doi.org/10.1111/1753-6405.12410 


\title{
VicHealth
}

\author{
Victorian Health Promotion Foundation \\ PO Box 154 Carlton South \\ Victoria 3053 Australia \\ $T+61396671333 F+61396671375$ \\ vichealth@vichealth.vic.gov.au \\ vichealth.vic.gov.au \\ twitter.com/vichealth \\ facebook.com/vichealth
}

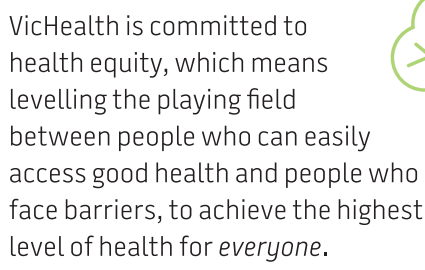

VicHealth acknowledges the support of the Victorian Government.

(c) VicHealth September 2020

https://doi.org/10.37309/2020.Cl910

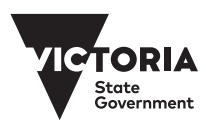

VicHealth acknowledges the Traditional Custodians of the land. We pay our respects to all Elders past, present and future. 